\title{
TRPV1 and TRPA1 Function and Modulation Are Target Tissue Dependent
}

\author{
Sacha Malin, ${ }^{1,4}$ Derek Molliver, ${ }^{1,2,4}$ Julie A. Christianson, ${ }^{5}$ Erica S. Schwartz, ${ }^{3,4}$ Pam Cornuet, ${ }^{1,4}$ Kathryn M. Albers, ${ }^{1,2,4}$ \\ and Brian M. Davis ${ }^{1,2,4}$ \\ ${ }^{1}$ Department of Medicine, Division of Gastroenterology, Hepatology and Nutrition, ${ }^{2}$ Department of Neurobiology, ${ }^{3}$ Department of Anesthesiology, and \\ ${ }^{4}$ Pittsburgh Center for Pain Research, University of Pittsburgh School of Medicine, Pittsburgh, Pennsylvania 15260, and ${ }^{5}$ Department of Anatomy and Cell \\ Biology, University of Kansas Medical Center, Kansas City, Kansas 66160
}

The nerve growth factor (NGF) and glial cell line-derived neurotrophic factor (GDNF) families of growth factors regulate the sensitivity of sensory neurons. The ion channels transient receptor potential vanilloid 1 (TRPV1) and transient receptor potential channel, subfamily A, member 1 (TRPA1), are necessary for development of inflammatory hypersensitivity and are functionally potentiated by growth factors. We have shown previously that inflamed skin exhibits rapid increases in artemin mRNA with slower, smaller increases in NGF mRNA. Here, using mice, we show that, in inflamed colon, mRNA for both growth factors increased with a pattern distinct from that seen in skin. Differences were also seen in the pattern of TRPV1 and TRPA1 mRNA expression in DRG innervating inflamed skin and colon. Growth factors potentiated capsaicin (a specific TRPV1 agonist) and mustard oil (a specific TRPA1 agonist) behavioral responses in vivo, raising the question as to how these growth factors affect individual afferents. Because individual tissues are innervated by afferents with unique properties, we investigated modulation of TRPV1 and TRPA1 in identified afferents projecting to muscle, skin, and colon. Muscle and colon afferents are twice as likely as skin afferents to express functional TRPV1 and TRPA1. TRPV1 and TRPA1 responses were potentiated by growth factors in all afferent types, but compared with skin afferents, muscle afferents were twice as likely to exhibit NGF-induced potentiation and one-half as likely to exhibit artemin-induced potentiation of TRPV1. Furthermore, skin afferents showed no GDNF-induced potentiation of TRPA1, but $43 \%$ of muscle and 38\% of colon afferents exhibited GDNF-induced potentiation. These results show that interpretation of afferent homeostatic mechanisms must incorporate properties that are specific to the target tissue.

\section{Introduction}

Primary sensory neurons located in dorsal root ganglia (DRGs) are highly diverse in regards to their anatomical, neurochemical, and functional characteristics (Lawson, 1992). Nociceptors, primary sensory neurons that detect noxious stimuli, innervate virtually every tissue in the body and are defined as $\mathrm{C}-$, $\mathrm{A} \delta$-, or $\mathrm{A} \beta$-fibers, according to their conduction velocity and association with unmyelinated, lightly myelinated, or heavily myelinated axons, respectively. Nociceptors are also neurochemically characterized into peptidergic [expressing calcitonin gene-related peptide (CGRP) and/or substance $\mathrm{P}$ (SP)] and nonpeptidergic populations. Broad phenotypic differences exist between these subgroups of nociceptors; peptidergic nociceptors primarily express trkA and are regulated by nerve growth factor (NGF), whereas nonpeptidergic afferents primarily express ret and are

Received June 11, 2010; revised April 26, 2011; accepted May 19, 2011.

Author contributions: S.M., D.M., J.A.C., E.S.S., P.C., K.M.A., and B.M.D. designed research; S.M., D.M., J.A.C., E.S.S., P.C., and B.M.D. performed research; S.M., D.M., J.A.C., K.M.A., and B.M.D. analyzed data; S.M., D.M., J.A.C., and B.M.D. wrote the paper.

This work was funded by NINDS Grants R01 31826 and 050758 (B.M.D.) and 033730 (K.M.A.) and NIDDK Grant K01 080182 (J.A.C.). We also thank Chris Sullivan for his outstanding technical support.

Correspondence should be addressed to Brian M. Davis, Department of Medicine/GI, E1440 Basic Medical Science Tower, University of Pittsburgh School of Medicine, 200 Lothrop Street, Pittsburgh, PA 15261. E-mail: bmd1@pitt.edu.

DOI:10.1523/JNEUROSCI.2992-10.2011

Copyright $\odot 2011$ the authors $\quad 0270-6474 / 11 / 3110516-13 \$ 15.00 / 0$ regulated by the glial cell line-derived neurotrophic factor (GDNF) family of ligands (GFL) (Molliver et al., 1995). Among trkA expressing C-fibers in mouse, approximately one-third also express GDNF family receptor $\alpha 3$ (GFR $\alpha 3)$, the specific coreceptor for artemin (ARTN), thereby rendering these afferents sensitive to both NGF and ARTN (Orozco et al., 2001).

Our laboratory and others have shown that the contribution of specific nociceptor subtypes toward peripheral innervation varies depending upon the target tissue. For example, although cutaneous and visceral structures are innervated by both peptidergic and nonpeptidergic C-fibers, at least $70 \%$ of visceral afferents are peptidergic (Robinson et al., 2004; Christianson et al., 2006a; Fasanella et al., 2008), whereas 70\% of epidermal afferents are nonpeptidergic (Lu et al., 2001; Lindfors et al., 2006). Interestingly, inflammatory hyperalgesia in both tissue types is regulated by nociceptors expressing the heat-gated channel transient receptor potential vanilloid 1 (TRPV1), which is predominantly expressed by peptidergic afferents and therefore more prevalent among visceral afferents than cutaneous (Caterina et al., 1997; Davis et al., 2000; Wick et al., 2006; Winston et al., 2007; Xu et al., 2007). In all tissues, inflammation is also accompanied by increases in NGF and/or other growth factors (Lewin et al., 1994; Woolf et al., 1994; Bielefeldt et al., 2003; Malin et al., 2006), which have been shown to sensitize nociceptors and produce hyperalgesia (Lewin and Mendell, 1994; Shu and Mendell, 1999; Amaya et al., 2004; Malin et al., 2006; Schmutzler et al., 2009). 
In the present study, we examined the relationship between TRP channels [TRPV1 and transient receptor potential channel, subfamily A, member 1 (TRPA1)] and growth factors in tissuespecific afferents. Peripheral tissues, such as skin, muscle, and viscera, are functionally specialized due to their exposure to distinct environmental stimuli. In this study, our central hypothesis is that sensory afferents innervating each tissue are also specialized in TRP channel and growth factor receptor expression, as well as in receptor coupling to intracellular signaling pathways. Examination of afferents innervating three different tissues (skin, muscle, and colon) revealed significant differences in TRPV1 and TRPA1 functional expression and subsequent growth factor modulation. Furthermore, inflammation in each of these tissues produced a different pattern of growth factor upregulation, paralleled by differential changes in primary afferent TRP channel mRNA expression. Our results indicate that, much like other nociceptor characteristics, the mechanisms regulating nociceptor plasticity are heterogeneous depending upon the peripheral target of the afferent.

\section{Materials and Methods}

Animals. Experiments were performed on 8-week-old male C57BL/6 mice (The Jackson Laboratory) housed in the Division of Laboratory Animal Resources at the University of Pittsburgh Medical Center. All research performed conformed to NIH guidelines and with procedures specified in the University of Pittsburgh Medical Center Animal Care and Use Protocols. All mice received water and food ad libitum.

Behavioral assay for growth factor potentiation of TRPV1 and TRPA1 responses. To determine whether growth factors potentiate TRPV1 or TRPA1 agonist effects in vivo, mouse hindpaws were injected with growth factor [100 ng of NGF, ARTN, neurturin (NRTN), and/or GDNF in $20 \mu \mathrm{l}$ of sterile saline] or $20 \mu \mathrm{l}$ of saline $30 \mathrm{~min}$ before either a subcutaneous injection of capsaicin ( $1 \mu \mathrm{g}$ in $5 \mu \mathrm{l}$ of $5 \%$ DMSO) or surface application of mustard oil ( $10 \%$ in $\sim 10 \mu \mathrm{l}$ of mineral oil) on the plantar surface of the hindpaw. This growth factor concentration was used because previous studies have shown it produces thermal hyperalgesia without overt nocifensive behaviors (Malin et al., 2006). Nocifensive responses (paw licking, biting, and/or lifting) to TRPV1 (capsaicin) or TRPA1 (mustard oil) agonists were monitored for $5 \mathrm{~min}$. At the end of the experiment, the extent of edema was also determined using a caliper to measure dorsoventral paw thickness. The amount of time that elapsed between application of capsaicin or mustard oil and measurement for edema was $\sim 45 \min (n=10$ male mice per TRP agonist per growth factor).

Induction of inflammation of skin and colon. To inflame mouse hindpaws, mice were anesthetized with $4 \%$ inhaled isoflurane and $20 \mu \mathrm{l}$ of complete Freund's adjuvant (CFA) emulsion was injected into the plantar surface of the foot bilaterally. All mice showed substantial hindpaw edema 1-3 d after CFA injection using a caliper micrometer. To inflame the colon, 4- to 6-week-old mice were anesthetized with $4 \%$ inhaled isoflurane and $0.25 \mathrm{mg}$ of trinitrobenzene sulfonic acid (TNBS) in $50 \mu \mathrm{l}$ of $50 \% \mathrm{EtOH}$ was infused into the colon using a 26 ga gavage needle. At each survival time point (naive baseline, 1, 4, 7, and $14 \mathrm{~d}$ after CFA or TNBS treatment), five adult male mice were given an overdose of Avertin anesthetic and transcardially perfused with $25 \mathrm{ml}$ of ice-cold $0.9 \%$ saline. For CFA-treated mice, bilateral L2-L5 DRGs were collected on dry ice and immediately processed for RNA isolation. For TNBS-treated mice, the distal $2 \mathrm{~cm}$ colon segment was removed and halved lengthwise for myeloperoxidase (MPO) assay and RNA isolation. Bilateral L5-S1 DRGs were also removed from these mice and processed for RNA.

Analysis of growth factor $m R N A$ in colon and TRPV1 and TRPA1 mRNA in skin and colon neurons. Tissue from each animal was processed separately. RNA was isolated by homogenizing frozen tissue in $2 \mathrm{ml}$ (colon) or $0.5 \mathrm{ml}$ (DRG) of Trizol reagent (Invitrogen) followed by isopropanol precipitation. Pellets were washed with $70 \%$ ethanol, suspended in RNase-free water, and the concentration determined using a GeneQuant RNA/DNA calculator (GE Healthcare). Five micrograms of RNA was treated with DNase (Invitrogen) to remove genomic DNA, and then $1 \mu \mathrm{g}$ was reverse transcribed using SuperScript II reverse transcriptase (Invitrogen).

Real-time PCR was used as previously described (Molliver et al., 2005) to determine the level of expression of growth factor mRNA in the colon and TRPV1 and TRPA1 expression in sensory neurons innervating the hindpaw (DRG L2-L5) and colon (DRG L5-S1) following CFA-induced footpad or TNBS-induced colon inflammation, respectively. Primers optimized for real-time PCR were designed using Oligo software (Molecular Biology Insights). SYBR Green PCR amplification was performed using an Applied Biosystems 5700 real-time thermal cycler. After amplification, a dissociation curve was plotted against melting temperature to ensure amplification of a single product. All samples were run in triplicate and control reactions were run without template and with the reverse transcriptase control reaction products as negative controls with every amplification run. The relative fluorescence of SYBR Green bound to double-stranded DNA was compared with a passive reference for each cycle. Threshold cycle $(\mathrm{Ct})$ values, the cycle number in which SYBR Green fluorescence rises above background, were recorded as a measure of initial template concentration. Relative fold changes in RNA levels were calculated by the $\Delta \Delta \mathrm{Ct}$ method using glyceraldehyde-3-phosphate dehydrogenase (GAPDH) as a reference standard (Livak and Schmittgen, 2001; Schmittgen and Livak, 2008): Ct values from triplicate samples were averaged and then subtracted from the reference standard, yielding $\Delta$ Ct. The differences between the $\Delta$ Ct of the different genes or of the experimental and control groups were then calculated $(\Delta \Delta \mathrm{Ct})$. The relative fold change was determined as $2^{-\Delta \Delta \mathrm{Ct}}$. Primer sequences were as follows $\left(5^{\prime}-3^{\prime}\right)$ : NGF (tccaatcctgttgagagtgg; caggctgtgtctatgcggat); ARTN (ctcagtctcctcagcccg; tccacggtcctccaggtg); GDNF (aaggtcaccagataaacaagcgg; tcacaggagccgctgcaatatc); NRTN (ggatgtgccaggagggtctg; caggtcgtagatgcggatgg); GAPDH (atgtgtccgtcgtggatctga; gctgttgaagtcgcaggagaca); TRPV1 (cccattgtgcagattgagcat; ttcctgcagaagagcaagaagc); TRPA1 (gcaggtggaacttcataccaact; cactttgcgtaagtaccagagtgg).

PCR cytokine/cytokine receptor assays for analysis of skin and colon inflammation. To compare the inflammatory milieu of CFA-inflamed skin and TNBS-inflamed colon SABiosciences PCR arrays were used (catalog \#PAM011). These arrays consist of 98-well plates that contain primers for 84 different cytokines, cytokine receptors, as well as, internal standards. Hindpaw skin was removed $3 \mathrm{~d}$ after CFA injection (the time of maximal inflammation), and colon was collected $1 \mathrm{~d}$ after TNBS treatment (time of maximal myeloperoxidase activity). RNA was extracted as described above and processed for SYBR Green PCR amplification according to the manufacturer's directions. Four inflamed colons and four footpads were compared with four naive controls for each tissue. Manufacturer's proprietary software (http://pcrdataanalysis.sabiosciences.com/pcr/arrayanalysis.php) was used to calculate fold changes in mRNA expression and to conduct statistical analysis (Student's $t$ test; significance, $p<0.05)$.

Single-cell PCR for detection of TRPA1 and TRPV1 in cutaneous afferents. To validate the percentage of neurons expressing functional TRPV1 and TRPA1 channels (as determined by calcium imaging) in muscle and cutaneous afferents, saphenous and femoral nerves were labeled with wheat germ agglutinin (WGA) as described above, and the L2-L4 DRGs were removed, dissociated, and grown acutely in culture $(\sim 2 \mathrm{~h})$. We also used these cells to determine the distribution of GFR $\alpha 1$ and GFR $\alpha 2$ expression, as these receptors are thought to be present in TRPV1- and TRPA1-expressing afferents at only low levels (below). Individual WGA-labeled neurons were collected with large-bore $(\sim 50$ $\mu \mathrm{m})$ glass pipettes and expelled into microcentrifuge tubes containing reverse transcriptase mix (Invitrogen). For each experiment, negative controls consisted of omitting reverse transcriptase or using a cell-free bath aspirate as template. The first-strand cDNA was used as template in a PCR reaction containing $1 \times$ GoTaq reaction buffer (Promega), $20 \mathrm{~mm}$ outer primers (nested primers were used to maximize sensitivity), 0.2 mm dNTPs, and $0.2 \mathrm{ml}$ GoTaq DNA polymerase (Promega); primer sequences are listed in Table 1. Each initial PCR product served as template in a subsequent PCR using a nested primer pair, the products of which were electrophoresed on $2 \%$ agarose-ethidium bromide gels and photographed. Only samples producing detectable amplification of a 
Table 1. DNA primers used for PCR amplification $\left(5^{\prime} \rightarrow 3^{\prime}\right)$ for single-cell analysis

\begin{tabular}{|c|c|c|c|}
\hline Gene (expected size) & External primers & Internal primers & Accession no. \\
\hline TRPA1 & СTTCCTGGATTACAACAATGCTCTG & CAGTGGCAATGTGGAGCAATAG & NM_177781 \\
\hline 495 bp, 224 bp & ATGTCCCCAACCGCCAAGC & AAGGAAAGCAATGGGGTGC & \\
\hline TRPV1 & GGGAAGAATAACTCACTGCCTGTG & GGCGAGACTGTCAACAAGATTGC & NM_001001445 \\
\hline 486 bp, 191 bp & TGGGTCCTCGTTGATGATGC & TCATCCACCCTGAAGCACCAC & \\
\hline GFR $\alpha 1$ & TGACCTGGAAGATTGCCTGAAG & TGCCACGACTACCACTGCCTTC & NM_010279.2 \\
\hline 359 bp, 134 bp & AGGAGCAGCCATTGATTTTGTG & GCCCGATACATTGGATTTCAGC & \\
\hline GFR $\alpha 2$ & TTTCCCTACATTGCCTCTGAACC & AAGGGACATCCAGCACCGAG & NM_008115.2 \\
\hline 249 bp, 120 bp & TTGTCCTTTCCCCAGTCCACAC & TCCACACCAGGCACAGCAAC & \\
\hline GAPDH & GCTGAGTATGTCGTGGAGTCTA & GTTTGTGATGGGTGTGAACCAC & NM_008084 \\
\hline 493 bp, 242 bp & CATACTTGGCAGGTTTCTCCAG & TGGATGCAGGGATCATGTTCTG & \\
\hline
\end{tabular}

Two sets for primers were used for single-cell analysis to increase sensitivity. GAPDH PCR was run first, and only cells that exhibited GAPDH mRNA were tested for TRPV1 and TRPA1.

positive control housekeeping gene (GAPDH) were analyzed for TRPA1 and TRPV1.

Myeloperoxidase assay. Myeloperoxidase activity was measured in distal colon to quantify the extent of neutrophil activation following intracolonic TNBS administration. Briefly, the distal $2 \mathrm{~cm}$ of colon was dissected, and the fecal matter, excess blood vessels, and mesentery were removed. The tissue was weighed, added to a beaker containing $1 \mathrm{ml}$ of $0.5 \%$ hexadecyltrumethylammonium bromide (HTAB) (Sigma-Aldrich) and finely minced using spring scissors. The solution was transferred to a $15 \mathrm{ml}$ centrifuge tube along with another $2 \mathrm{ml}$ of HTAB and sonicated for $10 \mathrm{~s}$ before being homogenized for $30 \mathrm{~s}$. Another $2 \mathrm{ml}$ of HTAB was added, and the tube was placed on dry ice until all samples were similarly collected. The samples underwent three freeze-thaw cycles, were centrifuged twice, and loaded, along with MPO standards (Calbiochem), onto a 96-well plate. The samples and standards were reacted with $O$-dianisidine dihydrochloride (Sigma-Aldrich) and read on a plate reader at $460 \mathrm{~nm}$ every $20 \mathrm{~s}$ for $15 \mathrm{~min}$. The slope for each standard reading was calculated and plotted and the slope of those values was used to calculate the units of MPO activity/ tissue weight for each sample.

Retrograde labeling of tissue-specific afferents. Six- to eight-week-old adult male C57BL/6 mice obtained from The Jackson Laboratory were used for all experiments. All surgical procedures were performed under sterile conditions in a designated animal surgery area. Mice were anesthetized by inhaled isoflurane ( $4 \%$ for induction, $2 \%$ for maintenance). For each of the structures that were examined, specific retrograde markers were used (below). These markers were chosen because previous studies had found that they labeled the greatest number of afferent fibers projecting to these targets (Wang et al., 1998; Christianson et al., 2006b).

For colon injections ( $n=148$ mice), a laparotomy was made to expose the pelvic viscera. Using a Hamilton microsyringe ( 33 ga needle), a single $5 \mu$ injection of Alexa Fluor 488-conjugated cholera toxin- $\beta$ (CTB) (2 $\mathrm{mg} / \mathrm{ml}$ ) was made beneath the serosal layer in the distal region of the colon, $1 \mathrm{~cm}$ proximal to the anus. The colon was swabbed to remove any excess of tracer, the wound was sutured and the mice recovered for $4 \mathrm{~d}$. Previously, we have applied $5 \mu \mathrm{l}$ of CTB onto the serosal surface of the distal colon (and adjacent tissues) to determine the extent of retrograde labeling that might arise from dye leakage. On average, this resulted in only two CTB-positive cells per section in the L6 ganglia (Christianson et al., 2006a).

To label muscle ( $n=72$ mice) and skin afferents ( $n=122$ mice), both right and left femoral or saphenous nerves were exposed and $\sim 0.5 \mu \mathrm{l}$ of Alexa Fluor 488-conjugated WGA (2\%) was injected into the nerve using a glass electrode and nitrogen-driven Picospritzer system. Saphenous nerve injection was performed at midthigh level (distal to muscle branch); femoral nerve injection was performed at groin level (distal to saphenous branch). To prevent leakage of tracer to surrounding tissues, Parafilm (Thermo Fisher Scientific) was placed under the nerves before injection and $\sim 30 \mu \mathrm{l}$ of gelatin ( $10 \%$ in $0.1 \mathrm{M}$ phosphate buffer) was applied following injection to seal the nerve sheath. The incision sites were sutured and the animals were allowed to recover for $3 \mathrm{~d}$. Each mouse received a single type of nerve injection. Very few $(<1 \%)$ labeled neurons were detected in culture when dye was applied onto the outside of the nerve without injection into the sheath, suggesting that leakage effects are minimal.
Calcium imaging. Mice were given an overdose of Avertin anesthetic and transcardially perfused with $4^{\circ} \mathrm{C} \mathrm{Ca}^{2+} / \mathrm{Mg}^{2+}$-free HBSS (Invitrogen). Bilateral L2-L4 or L5-S1 DRGs were dissected into HBSS for saphenous/femoral or colon injected mice, respectively, and ganglia were dissociated as previously described (Malin et al., 2007). Cells were plated in F12 media (Invitrogen) containing 10\% fetal calf serum and antibiotics (penicillin/streptomycin, $50 \mathrm{U} / \mathrm{ml}$ ), with no additional growth factors added to the culture medium. $\mathrm{Ca}^{2+}$ imaging was performed $18-24 \mathrm{~h}$ after plating. Before imaging, the cells were incubated with $2 \mu \mathrm{M}$ fura-2 (Invitrogen) in HBSS containing $5 \mathrm{mg} / \mathrm{ml}$ BSA (Sigma-Aldrich) for 30 min at $37^{\circ} \mathrm{C}$. Coverslips were mounted on an Olympus inverted microscope stage with constantly flowing buffer at $5 \mathrm{ml} / \mathrm{min}$. Perfusion rate was controlled with a gravity flow system (Warner Instruments), and perfusate temperature was maintained at $30^{\circ} \mathrm{C}$ using a heated stage and an in-line heating system (Warner Instruments). Drugs were delivered with a rapid-switching local perfusion system. Firmly attached, refractile cells containing retrograde label (skin, muscle, and colon neurons) were identified as regions of interest in the software (Simple PCI; C-Imaging). All fields were first tested with brief application (4s) of $50 \mathrm{~mm} \mathrm{~K}^{+}$(high $\mathrm{K}^{+}$) and $\mathrm{Ca}^{2+}$ transients were imaged to standardize pipette placement and to ensure that cells were healthy and responsive. Only cells responsive to high $\mathrm{K}^{+}$application were analyzed further. In the standard protocol, cells were first tested with two to three presentations of capsaicin (1 $\mu \mathrm{M})$ or mustard oil $(100 \mu \mathrm{M})$ at 10 min intervals. Capsaicin at $1 \mu \mathrm{M}$ was found to elicit a response $>0.1 \Delta F_{340 / 380}$ from the maximal number of cells and could be applied repeatedly without significant loss in the number of responding cells over more than four applications. Mustard oil at $100 \mu \mathrm{M}$ was also found to elicit a response $>0.1 \Delta F_{340 / 380}$ from the maximal number of cells; however, repeated mustard oil presentations showed significant loss in the number of responding cells over more than four applications due to pronounced tachyphylaxis. Mustard oil and capsaicin were sequentially applied at $40 \mathrm{~min}$ intervals to determine the extent of TRPV1 and TRPA1 overlap in identified afferents; percentage responders for each agonist did not vary with agonist presentation order. Absorbance data at 340 and $380 \mathrm{~nm}$ were collected at one frame per second. Responses were measured as the ratio of $340 / 380 \mathrm{~nm}$ excitation and $510 \mathrm{~nm}$ emission $\left(\Delta F_{340 / 380}\right.$; DG4; Sutter Instrument). Peak responses $>0.1 \Delta F_{340 / 380}$ were included in the analysis and were easily distinguishable from optical noise $\left(<0.02 \Delta F_{340 / 380}\right)$. Mean \pm SEM data (peak and area $\Delta F_{340 / 380}$ ) presented are derived from the initial agonist presentation. Non-retrogradely labeled cells within the imaging field provided a positive control for TRPV1 and TRPA1 agonist application.

Capsaicin and mustard oil response data were obtained before and after a $7 \mathrm{~min}$ perfusion of growth factor $(100 \mathrm{ng} / \mathrm{ml} \mathrm{NGF}$, GDNF, ARTN, or NRTN). Capsaicin and mustard oil experiments were performed on separate coverslips, and responses to individual growth factors were also tested separately. Responses were then allowed to recover to determine the time course of growth factor action on TRPV1 and TRPA1 (generally $<30 \mathrm{~min}$ ). Growth factors were also tested sequentially to determine the extent to which TRPV1 and TRPA1 are modulated by multiple trophic factors. $\mathrm{Ca}^{2+}$ response area data is presented as the ratio of post-growth factor capsaicin and mustard oil responses to naive capsaicin and mustard oil responses in individual cells $\left(\Delta F_{\text {area }}\right)$. 

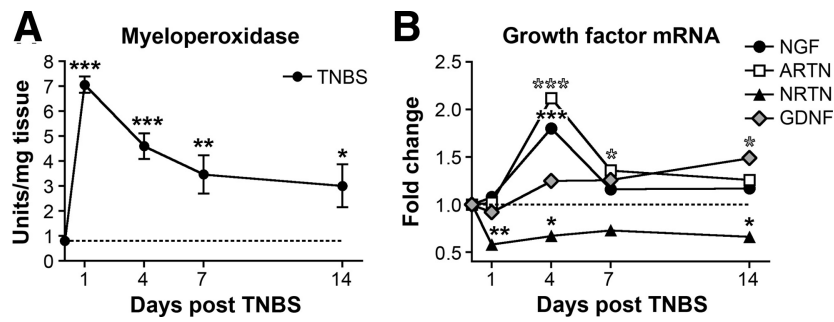

Figure 1. Expression of growth factors is altered in inflamed tissue. $\boldsymbol{A}$, Myeloperoxidase assay reveals that TNBS induces rapid inflammation within $24 \mathrm{~h}$ of TNBS instillation in the colon. Inflammation begins to resolve by day 4 but remains elevated for at least 2 weeks. $\boldsymbol{B}$, The time course and magnitude of changes in growth factor mRNA levels in the colon during TNBSinduced colonic inflammation was measured by real-time PCR. NGF and ARTN exhibit parallel increases in expression that peak at day 4. GDNF increases more slowly and remains elevated at 2 weeks, whereas NRTN is immediately decreased and remains so for at least 2 weeks. ${ }^{*} p<$ $0.05,{ }^{* *} p<0.01,{ }^{* * *} p<0.001$ versus naive; two-way ANOVA with Bonferroni's posttest. Error bars indicate SEM.

Capsaicin (Sigma-Aldrich) was dissolved in 1-methyl-2-pyrrolidinone to create a $10 \mathrm{~mm}$ stock solution; $1.0 \mu \mathrm{M}$ capsaicin was made fresh daily in HBSS. Mustard oil (Fluka) was dissolved in 1-methyl-2pyrrolidinone to create a $100 \mathrm{~mm}$ stock solution and diluted to $100 \mu \mathrm{M}$ in HBSS. All mustard oil solutions were made fresh every $3 \mathrm{~h}$, and mustard oil stocks maintained under nitrogen. Aliquots of NGF (Harlan), ARTN (R\&D Systems), NRTN (R\&D Systems), and GDNF (Calbiochem) at 10 $\mathrm{mg} / \mathrm{ml}$ in HBSS were stored at $-20^{\circ} \mathrm{C}$ and diluted in HBSS immediately before use. Growth factor concentrations are given in nanograms per milliliter; these factors have similar molecular weights (in kDa: $26 \mathrm{NGF}$, 24 ARTN, 23 NRTN, 30 GDNF). However, it is worth noting that, because GDNF weighs slightly more than NGF, NRTN, or ARTN, the molar concentration of GDNF is slightly less than the other growth factors at the same nanogram per milliliter dose.

Statistical analysis. Calculations were made using Microsoft Excel and statistical analysis performed using Mann-Whitney, one-way or twoway ANOVA followed by an appropriate posttest (GraphPad Prism; GraphPad Software) as indicated in the figure legends. All data are expressed as mean \pm SEM. A value of $p>0.05$ was considered significant.

\section{Results}

Inflammation increases growth factor and TRP expression differentially in skin and colon

Previous studies have reported changes in growth factor expression in inflamed skin (Ji et al., 2002; Amaya et al., 2003, 2004; Malin et al., 2006). Specifically, we reported that ARTN mRNA increases 10 -fold in skin within $24 \mathrm{~h}$ of CFA injection; this change is followed by slower and more modest increases in NGF and NRTN mRNAs (Malin et al., 2006). In the current study, we investigated the effects of inflammation on growth factor mRNA expression in the colon to determine whether different tissues have unique patterns of inflammation-induced growth factor expression. Intracolonic administration of TNBS produced a robust inflammation, lasting up to $14 \mathrm{~d}$, as measured by myeloperoxidase assay (Fig. 1A). An approximately twofold increase in both NGF and ARTN mRNAs was observed $4 \mathrm{~d}$ after TNBS administration (Fig. $1 B$ ). This is a smaller and slower increase in ARTN and similar, yet faster, increase in NGF when compared with CFA-induced inflammation in the hindpaw (Malin et al., 2006). GDNF mRNA expression increased more slowly and did not become significantly elevated until day 14 post-TNBS treatment, unlike following CFA-induced hindpaw inflammation, which produces a significant decrease in GDNF mRNA expression (Malin et al., 2006). NRTN mRNA decreased almost immediately and remained reduced from baseline for at least
$14 \mathrm{~d}$, similar to our previous observations following hindpaw inflammation.

The observed difference in TRPV1 and TRPA1 seen in skin and colon afferents following inflammation of their respective target tissues suggested that inflammation in these two tissues was not equivalent. That is, CFA-induced inflammation of skin and TNBS-induced inflammation of the colon induced tissuespecific changes in the inflammatory milieu. To examine this issue real-time PCR arrays (SABiosciences) were used to quantify the level of 84 different cytokines or cytokine receptors following induction of inflammation using two of the most common methods of inflaming skin and colon. Tissue from skin and colon were collected and analyzed at the time point of maximal inflammation as indicated by behavioral hypersensitivity and swelling for skin (3 d after injection) or maximal myeloperoxidase activity for colon ( $1 \mathrm{~d}$ after TNBS).

In terms of mRNA expression, inflammation of these tissues resulted in very different cytokine mRNA profiles (supplemental Tables 1, 2, available at www.jneurosci.org as supplemental material). In skin, 35 of 84 cytokine or cytokine receptor genes exhibited significant changes ( $p<0.05$, Student's $t$ test); 24 were increased, while 11 were decreased. In colon, 19 genes exhibited changes, with 7 of these showing an increase. Of the genes that were changed in the inflamed colon, only 5 were altered in a similar manner in skin (i.e., increased or decreased in both skin and colon). ATP binding cassette subfamily 1 (ABCf1) was decreased 25 and $50 \%$ in colon and skin, respectively. In a gene linkage study, $\mathrm{ABCf} 1$ has been identified recently as a protein that may contribute to susceptibility to autoimmune pancreatitis (Ota et al., 2007). Not much is known of the function of this gene other than it may be involved in initiation of translation (Paytubi et al., 2009) and that it can be regulated by tumor necrosis factor (TNF) (Richard et al., 1998; Semov et al., 2002). Interestingly, TNF was significantly upregulated in both inflamed skin and colon (2.1- and 3.6-fold, respectively). Another gene that is potentially regulated by TNF, chemokine receptor 2 (CCR2) (Subang and Richardson, 2001; Glabinski et al., 2003), was also increased in skin and colon (3.6- and 2.1-fold, respectively). CCR2 is a $\beta$ chemokine receptor that binds a number of proteins in the MCP (monocyte chemoattractant protein) family. It is expressed on cells in the monocyte/macrophage lineage as well as on sensory neurons themselves (Oh et al., 2001; White et al., 2005). Tollip, a protein that was originally identified as interacting with the interleukin 1 receptor (Illr) (Burns et al., 2000) and more recently as a mediator of protein sumoylation (Ciarrocchi et al., 2009), was decreased in both inflamed skin and colon (decreased 31 and $35 \%$, respectively). Moreover, interleukin $1 \beta$ $(\mathrm{Il} 1 \beta)$, a proinflammatory cytokine that binds Ill $\mathrm{r}$, is increased in both inflamed colon and skin (3.59- and 42.56-fold, respectively), suggesting that the Ill $\beta$ pathway is common both to inflamed skin and colon.

These results show that, while there are important commonalities in CFA-inflamed skin and TNBS-inflamed colon, the cytokine profiles are unique. However, despite these differences, both ARTN and NGF are increased in both tissues, and these changes are correlated with an increase in the TRPV1 and TRPA1 in the neurons innervating both structures (below).

Changes in TRPV1 and TRPA1 mRNA expression in sensory neurons have been reported in models of inflammatory pain (Ji et al., 2002; Amaya et al., 2004; Molliver et al., 2005; Obata et al., 2005; Malin et al., 2006; Diogenes et al., 2007; Xu et al., 2007). To determine whether TRPV1 and TRPA1 expression is differentially modulated by inflammation in visceral versus cutaneous 

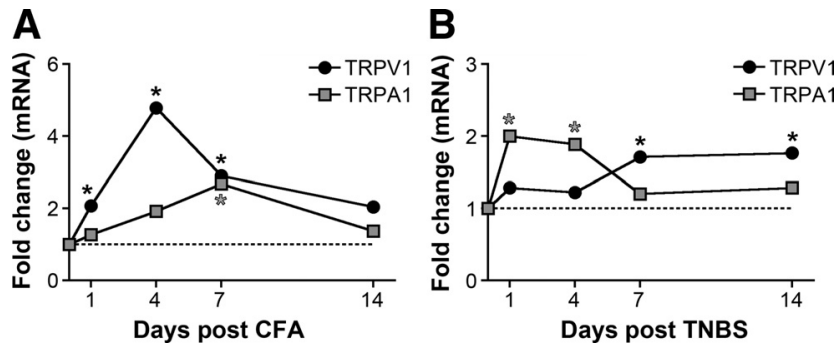

Figure 2. TRP channel expression is modulated during inflammation. The time course and magnitude of changes in TRP channel mRNA expression in L2-L5 DRG during CFA-induced inflammation $(\boldsymbol{A})$ and in L5-S1 DRG following TNBS-induced colon inflammation $(\boldsymbol{B})$ was measured by real-time $P C R$. Following skin inflammation, TRPV1 mRNA increases faster than TRPA1 mRNA expression; however, the pattern is reversed for colon inflammation. ${ }^{*} p<0.05$ versus naive; two-way ANOVA with Bonferroni's posttest.

tissue, we examined TRP mRNA expression in sensory neurons following CFA application to the skin or TNBS application to the colon. Following induction of skin inflammation, expression of TRPV1 mRNA was increased in DRG projecting to the hindpaw (L2-L4) (Fig. 2A). This increase in TRPV1 expression was evident at $24 \mathrm{~h}$ and peaked at $4 \mathrm{~d}$, as previously reported (Molliver et al., 2005; Malin et al., 2006). TRPA1 mRNA expression was also increased, albeit on a slower time course, reaching significance at day 4 and peaking at day 7. Interestingly, TRP channel expression was differentially modulated following inflammation of the colon. Following TNBS instillation, a significant increase in TRPV1 expression in DRG projecting to pelvic viscera (L5-S1) was not observed until day 7 , whereas TRPA1 expression was significantly increased within $24 \mathrm{~h}$ (Fig. $2 \mathrm{~B}$ ).

\section{TRPV1 and TRPA1 function is potentiated by growth factors} in vivo

Previous studies have shown that TRPV1 and TRPA1 channel functionality is potentiated in inflamed tissue, and mice containing null mutations for these channels exhibit decreased, or absent, inflammatory hyperalgesia (Caterina et al., 2000; Davis et al., 2000; Obata et al., 2005; Bautista et al., 2006; Kwan et al., 2006). These data suggest a fundamental role for TRP channel modulation in inflammatory hyperalgesia. We have shown previously that a brief application of growth factor (NGF, ARTN, NRTN, or GDNF) can potentiate capsaicin-induced calcium transients in isolated sensory neurons (Malin et al., 2006). However, we could find no reports of similar potentiation in vivo. To investigate the ability of growth factors to modulate TRP channel function in vivo, TRPV1- or TRPA1-specific agonists (capsaicin or mustard oil, respectively) were applied to the plantar surface of wild-type mouse paws $30 \mathrm{~min}$ after injection of $20 \mu \mathrm{l}$ of growth factor (100 ng of NGF, ARTN, NRTN, and/or GDNF in saline) or saline, and the resulting nocifensive behaviors were observed and recorded. As shown in Figure 3, pretreatment with growth factor significantly increased the number of nocifensive behaviors typically associated with capsaicin or mustard oil application (e.g., paw licking and biting), with the exception of GDNF that did not affect mustard oil responses. In addition, mustard oil-induced edema was increased in mice pretreated with all growth factors (percentage increase in mustard oil-induced edema following: saline, $15 \pm 2 \%$; NGF, $27 \pm 1 \%$; ARTN, $24 \pm 1 \%$; NRTN, $24 \pm$ $1 \%$; GDNF, $29 \pm 3 \%$; $p<0.001$, for all growth factors vs saline). Because of the highly penetrating nature of mustard oil preparation, the site of action for the production of edema is not clear. Data presented below indicate that GDNF does not potentiate
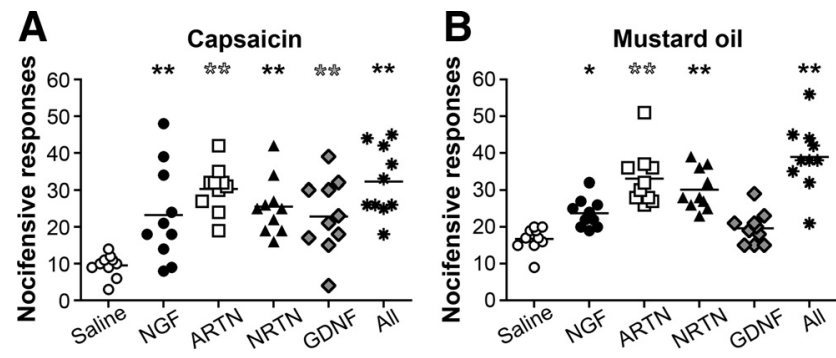

Figure 3. Growth factors potentiate TRP function in vivo. Mice were injected with growth factor $(0.2 \mathrm{mg} / 20 \mu \mathrm{l})$ or saline $(20 \mu \mathrm{l})$ in one hindpaw and 30 min later, $1 \mu \mathrm{g}$ of capsaicin $(\boldsymbol{A})$ or $10 \%$ mustard oil $(\boldsymbol{B})$ was applied to the growth factor/saline injected hindpaw. Nocifensive behaviors were monitored for $5 \mathrm{~min}$. NGF, ARTN, or NRTN preinjection increased the number of responses elicited by either capsaicin or mustard oil, compared with saline. GDNF was only effective in increasing the capsaicin response and had no effect on mustard oil responses. ${ }^{*} p<$ $0.05,{ }^{* *} p<0.01$ versus saline; one-way ANOVA with Dunnett's multiple-comparison test.

TRPA1 responses of skin afferents and this is also supported by the lack of increased nocifensive behaviors when GDNF is applied before mustard oil. This suggests that the increase in edema seen following GDNF is due to its effect on structures in deeper tissues (and this may also be true for the other growth factors).

At the concentration used in these experiments, capsaicin produced redness, but no overt swelling. Importantly, no redness or swelling was observed following injection of growth factor (before capsaicin or mustard oil application) indicating that, at the concentrations used, growth factors do not induce edema on their own.

\section{Functional TRPV1 and TRPA1 channels are significantly less} common in skin than in muscle or colon neurons

Although exact numbers vary depending on species studied and methodologies used, most investigators agree $\sim 50 \%$ of all C-fibers express TRPV1, and that at least one-half of these fibers also express TRPA1 (Bautista et al., 2005; Kobayashi et al., 2005; Elitt et al., 2006). Because of its proposed role in thermal detection, TRPV1 was originally thought to be highly expressed among cutaneous afferents; however, it was ultimately shown to be more widely expressed among neurons innervating deeper structures (Zwick et al., 2002; Woodbury et al., 2004; Christianson et al., 2006b). Given the extensive coexpression of TRPV1 and TRPA1, it could also be inferred that few cutaneous afferents would express TRPA1. To investigate this issue, retrograde tracers were used to label muscle afferents (via femoral nerve injection just proximal to its insertion into the vasti muscles), cutaneous afferents (via injections of the saphenous nerve, the largest cutaneous branch of the femoral nerve), and visceral (colon) afferents (via injections directly into the wall of the colon). Sensory neurons from L2-L4 DRG were isolated to obtain saphenous and femoral afferents, whereas sensory neurons from L5-S1 were used to examine colon afferents.

To determine the prevalence of functional TRPV 1 and TRPA1 expression among skin, muscle, and colon neurons, $\mathrm{Ca}^{2+}$ imaging was performed on isolated retrogradely labeled neurons during presentation of capsaicin and mustard oil. As expected, a significantly smaller percentage of skin afferents responded to capsaicin (31\%), compared with $67 \%$ for muscle afferents and $74 \%$ for colon afferents (Fig. $4 A$ ). Similar results were seen for TRPA1 responses: 19\% of skin afferents exhibited functional TRPA1 channels, whereas $53 \%$ of muscle afferents and $70 \%$ of colon afferents exhibited calcium transients in response to mustard oil (Fig. 4D). The size of the calcium signal was correlated 
A
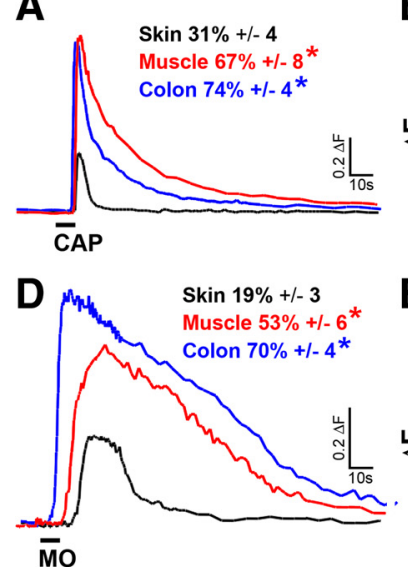

B

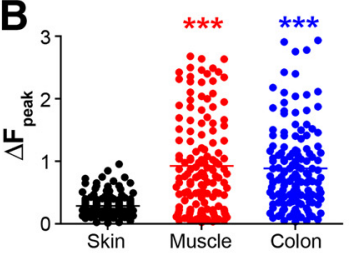

E

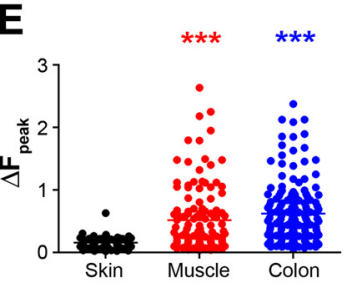

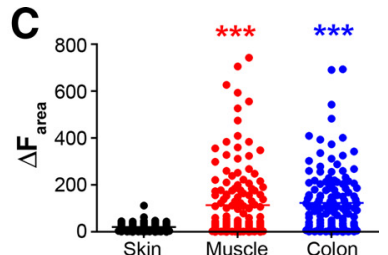

$\mathbf{F}$

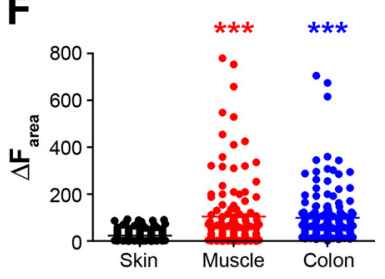

Figure 4. TRPV1 and TRPA1 expression is target tissue dependent. Afferents identified by injection of retrograde tracers into the saphenous nerve (WGA-488; skin), femoral nerve (WGA-488; muscle), or the colon wall (CTB-488) were characterized by Ca ${ }^{2+}$ imaging in vitro. Neurons innervating different target tissues showed substantial differences in the response kinetics to capsaicin ( $\boldsymbol{A}-\boldsymbol{C} ;$ TRPV1) and mustard oil ( $\boldsymbol{D}-\boldsymbol{F}$; TRPA1). Percentage responders for each agonist within the identified populations reveal fewer capsaicin and mustard oil responses in skin, compared with muscle and colon afferents. Representative traces of TRPV1 (A) and TRPA1 $(\boldsymbol{D})$ responses from skin (black), muscle (red), and colon (blue) afferents are overlaid to illustrate differences in response size. Mean peak and area of capsaicin $(\boldsymbol{B}, \boldsymbol{C})$ and mustard oil $(\boldsymbol{E}, \boldsymbol{F})$ responses are significantly smaller in skin afferents compared with muscle and colon afferents. ${ }^{*} p<0.01,{ }^{* * *} p<0.001$ versus skin; Mann-Whitney test.

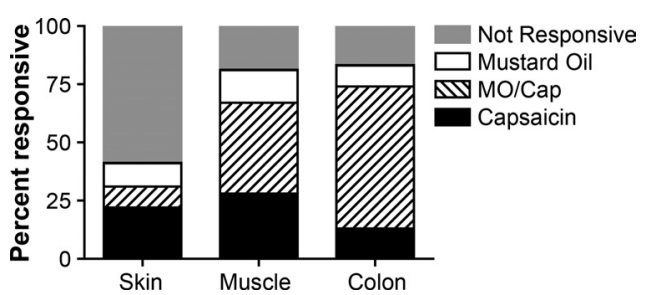

Figure 5. Coexpression of TRPV1 and TRPA 1 is target tissue dependent. $\mathrm{Ca}^{2+}$ imaging was performed to determine the percentage of retrogradely labeled skin, muscle, and colon neurons that respond to capsaicin and/or mustard oil. The percentage of neurons that express only TRPV1 (capsaicin responsive; black bar) or TRPA1 (mustard oil responsive; white bar) is not significantly different between the three afferent populations. In contrast, the percentage of neurons that express both TRPV1 and TRPA1 (hashed bar) is significantly larger in muscle and colon afferents than in skin afferents $(p<0.01)$. Significantly more nonresponsive (gray bar) skin neurons are observed than muscle or colon neurons ( $p<0.01$; one-way ANOVA with Dunnett's multiple-comparison test).

with the prevalence of both TRPV1 and TRPA1 responses. Skin afferents were not only less likely to respond to TRPV1 and TRPA1 agonists, but the calcium signals elicited by TRP agonists were significantly smaller (peak or area) than those recorded from either muscle or colon afferents (Fig. $4 B, C, E, F$ ). This was especially true for TRPA1 responses in skin afferents, which averaged only $25 \%$ of those recorded from muscle or colon afferents.

Retrogradely labeled skin, muscle, and colon afferents were probed with both capsaicin and mustard oil to determine the overlap in functional TRPV1 and TRPA1 expression (Fig. 5). Although all three populations of identified neurons contained similar percentages that responded to only one agonist, the percentage of neurons responding to both agonists was significantly smaller among skin neurons. In fact, more skin afferents responded to only one agonist (mustard oil only, 10\%; capsaicin only, 22\%) than responded to both (9\%). In contrast, a significantly greater percentage of both muscle and colon neurons responded to both agonists (muscle, 39\%; colon, 61\%) than to either agonist alone, indicating different levels of coexpression for these two receptors among neurons that innervate more superficial structures versus those that innervate deeper structures.

Previous studies from our laboratories and others (Kobayashi et al., 2005; Elitt et al., 2008) suggested that the majority of TRPA1-expressing afferents also express TRPV1. The functional data described above suggest that, especially for cutaneous afferents, this is not the case. To validate this finding, cutaneous afferents were retrogradely labeled and analyzed by single-cell PCR to determine the percentage of afferents that express TRPV1 and/or TRPA1 mRNA. For these studies, cells were cultured acutely $(\sim 2 \mathrm{~h})$ to minimize changes that might occur in the dish. These single-cell studies reveal that the majority of cutaneous afferents that express TRP channel mRNA express either TRPV1 or TRPA1 but not both: only $10 \%$ (3 of 32 ) of backlabeled cutaneous afferents expressed both TRPV1 and TRPA1, whereas $22 \%$ ( 7 of 32 ) of cutaneous afferents express TRPV1 mRNA alone and 6\% (2 of 32) expressed TRPA1 mRNA alone. Thus, the percentage of cutaneous afferents expressing mRNA for TRPV1 and/or TRPA1 was similar to that revealed in the calcium imaging studies.

The above experiments indicate that a significantly higher percentage of muscle and colon afferents express TRPV1 and TRPA1 compared with cutaneous afferents; however, these data do not provide an indication as to what percentage of TRPV1- or TRPA1-expressing afferents innervate skin, muscle, or colon. To address this question, we performed the opposite analysis of the above experiments and analyzed the percentage of capsaicinresponsive neurons in a given field that contained retrograde label from skin, muscle, or colon. In a typical field of sensory neurons isolated from L2-L4 DRG, $\sim 49 \pm 3 \%$ of all neurons responded to capsaicin. Of those capsaicin-responsive neurons, only $15 \pm 2 \%$ were retrogradely labeled from saphenous nerve. Nearly twice as many capsaicin-responsive neurons, $33 \pm 2 \%$, were retrogradely labeled from the femoral nerve. These data suggest that muscle afferents constitute a greater share of the TRPV1-expressing population than do skin afferents. This is further supported by the observation that twice as many neurons were retrogradely labeled by saphenous injection (six to seven cells per $40 \times$ field) than by femoral injection (three to four cells per $40 \times$ field); therefore, even though twice as many retrogradely labeled skin afferents were present in culture, muscle afferents were twice as likely to be among the capsaicin-responsive neurons. In a typical field of sensory neurons isolated from L5-S1 DRG, $58.0 \pm 1.0 \%$ responded to capsaicin. Of those capsaicinresponsive neurons, $5 \% \pm 1.0$ were retrogradely labeled from the distal colon. Despite the relatively small number of backlabeled colon afferents in L5-S1, it likely that a large percentage of the nonlabeled capsaicin-responsive neurons are innervating other pelvic visceral structures based on the spinal distribution patterns of bladder (Christianson et al., 2007) and both male and female reproductive organs (Berkley et al., 1988, 1990, 2005; Baron and Jänig, 1991; Keast and De Groat, 1992). Although this experiment represents an incomplete survey of skin, muscle, and visceral afferents located in the lumbar DRG, the discrepancies be- 

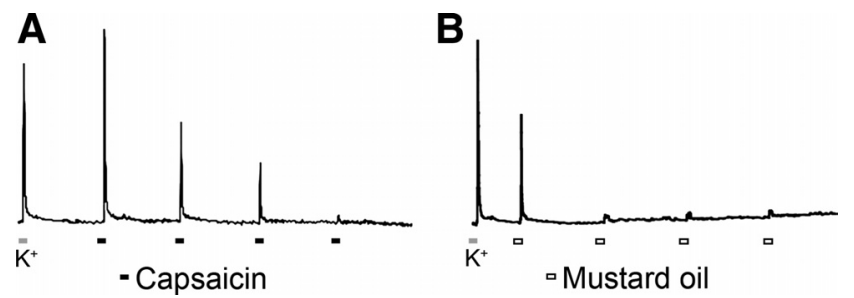

Figure 6. Repeated application of TRPV1 or TRPA1 agonist produces tachyphylaxis. $\mathrm{Ca}^{2+}$ imaging of responses to repeated $1 \mu \mathrm{m}$ capsaicin $(\boldsymbol{A})$ or $100 \mu \mathrm{m}$ mustard oil $(\boldsymbol{B})$ application in isolated mouse DRG neurons reveals profound desensitization of TRPV1 $(\boldsymbol{A})$ and TRPA1 (B) channels. Agonists were applied at 10 min intervals.

tween saphenous and femoral neurons and the significantly higher percentage of capsaicin-responsive neurons in lower lumbar DRG strongly suggest that most TRPV1-expressing, and presumably TRPA1-expressing, neurons are not innervating cutaneous structures.

\section{Growth factors differentially potentiate TRPV1 and TRPA1} responses in afferents innervating skin, muscle, and colon

Both TRPV1 and TRPA1 responses show tachyphylaxis to repeated agonist applications (Fig. 6) (Shu and Mendell, 1999; Malin et al., 2006; Akopian et al., 2007). We have previously demonstrated that NGF and GDNF family members can reverse capsaicin-induced tachyphylaxis in dissociated sensory neurons and even potentiate responses to repeated capsaicin application (Malin et al., 2006). We wanted to determine whether TRPV1 and TRPA1 responses in target-defined populations of sensory neurons are differentially modulated by exogenous growth factor application. Agonists for TRPV1 or TRPA1 were given at $10 \mathrm{~min}$ intervals and saline or growth factor (NGF, ARTN, NRTN, or GDNF) was present in the bath solution for $7 \mathrm{~min}$ between the first and second agonist presentations. For clarity, only those cells for which the size of the calcium signal in response to capsaicin or mustard oil after growth application was equal to or greater than that before growth factor application (i.e., post-growth factor/ pre-growth factor ratio $\geq 1$ ) was considered to be potentiated.

Figure 7 shows that the ability of growth factors to potentiate the response to capsaicin is highly specific for afferents innervating different tissues. For cutaneous afferents, ARTN was the most effective with respect to both the percentage of neurons affected (81\%) and the size of this effect. NGF and NRTN potentiated TRPV1 in a similar percentage of skin neurons (52 and 56\%, respectively), while GDNF potentiated the smallest percentage of TRPV1-expressing skin neurons. Among muscle afferents, NGF potentiated the greatest percentage of TRPV1 responses (79\%); in contrast, GDNF potentiated the smallest percentage of TRPV1expressing neurons and did not produce a significant increase in $\Delta F_{\text {area }}$. All four growth factors similarly affected TRPV1 responses in colon afferents, with twice as many responding to NGF or ARTN than NRTN or GDNF. It should also be noted that, for all afferent types, NRTN potentiation of capsaicin responses often took longer to develop; that is, we needed to wait up to $20 \mathrm{~min}$ to see the potentiation of the capsaicin response (Fig. 7). We have reported this previously (Malin et al., 2006). The reason for this difference is unknown but must be related to some unique property of the signaling pathway used by NRTN. This temporal difference is not universal for all NRTN effects as it was not seen for the mustard oil responses (Fig. 8).

Mustard oil responses were potentiated in a similar percentage of neurons for all three classes of afferents by NGF, ARTN, and NRTN (Fig. 8). However, several notable differences were observed. Most striking was the lack of GDNF-induced potentiation of mustard oil responses in skin neurons, whereas 43 and $38 \%$ of muscle and colon neurons, respectively, exhibited potentiation following GDNF exposure. It should be noted that the lack of potentiation by GDNF in cutaneous afferents could have been predicted from the behavioral results: GDNF was the only trophic factor that failed to increase nocifensive behavior induced by mustard oil application to the footpad (Fig. 3).

Previous studies have shown that, in mouse, $>90 \%$ of all GFR $\alpha 3$-positive neurons, and 22\% of GFR $\alpha 2$-immunopositive afferents, express TRPV1 (Orozco et al., 2001; Elitt et al., 2006). There is little data on the overlap between GFR $\alpha 1$ and TRPV1 and no data on the overlap between any GFR $\alpha$ receptors and TRPA1. Moreover, while there is a general consensus that TRPV1 and TRPA 1 are highly expressed in the peptidergic primary afferents [including the GFR $\alpha 3$-population (Orozco et al., 2001)], it is generally thought that nonpeptidergic neurons, including those that express GFR $\alpha 1$ and GFR $\alpha 2$ express little, if any, TRPV1 (Zwick et al., 2002). Because the calcium imaging data indicated significant potentiation of TRPV1 and TRPA1 responses by GDNF and NRTN, we performed single-cell PCR to determine the percentage of cutaneous and muscle afferents that express GFR $\alpha 1$ and GFR $\alpha 2$ and what proportion of these neurons expressed TRPV1 and TRPA1 (Table 2).

GFR $\alpha 1$ and GFR $\alpha 2$ are expressed at high levels in both cutaneous and muscular afferents, and it appears that, in a majority of cutaneous neurons, they are coexpressed as well. In both cutaneous and muscle afferents, a significant number of GFR $\alpha 1$ neurons express TRPV1. TRPA1 is expressed in a minority of GFR $\alpha 1$ cutaneous and muscle afferents. Although GFR $\alpha 2$ is expressed in a smaller percentage of muscle afferents compared with cutaneous afferents, a greater percentage of muscle GFR $\alpha 2$-expressing afferents express TRPA1.

Many of the cutaneous afferents potentiated by NGF showed barely detectable calcium signals in response to the first mustard oil application; only after exposure to NGF did they exhibit clear responses. Mustard oil responses from muscle and colon neurons were nearly identically affected by exposure to all growth factors tested, with the exception of GDNF, which elicited a greater magnitude of response in colon neurons $(5.2 \pm 1.1$-fold increase in $\left.\Delta F_{\text {area }}\right)$ than in muscle neurons $(3.6 \pm 0.9)$. Interestingly, growth factor-induced increases in response magnitude were twofold to fourfold greater for TRPA1 than for TRPV1 in both muscle and colon neurons. Together, these data not only support previous evidence of growth factor potentiation of TRP channel function, they also illustrate the importance of considering the peripheral target when analyzing growth factor effects on sensory neurons, as these vary markedly between skin, muscle, and colon afferent populations (Malin et al., 2006).

To confirm the receptor specificity of the growth factor actions, we tested ARTN-induced potentiation in DRGs from mice containing a null mutation in GFR $\alpha 3$ (Honma et al., 2002). Both capsaicin and mustard oil responses were less prevalent among sensory neurons isolated from GFR $\alpha 3^{-/-}$mice (supplemental Fig. $1 A, B$, available at www.jneurosci.org as supplemental material). The magnitude of mustard oil response was also reduced in this genetic background, compared with wild-type mice (data not shown). As expected, ARTN did not potentiate capsaicin or mustard oil responses remaining in neurons lacking GFR $\alpha 3$; however, NGF potentiation of both TRPV1 and TRPA1 remained unchanged in GFR $\alpha 3^{-1-}$ neurons (supplemental Fig. 1C-F, available at www.jneurosci.org as supplemental material). 
A

Skin

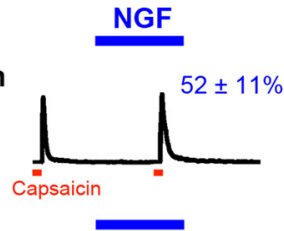

Muscle

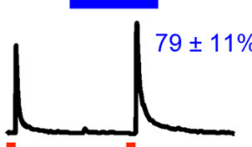

Colon

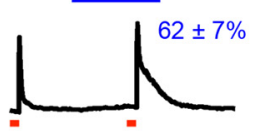

B

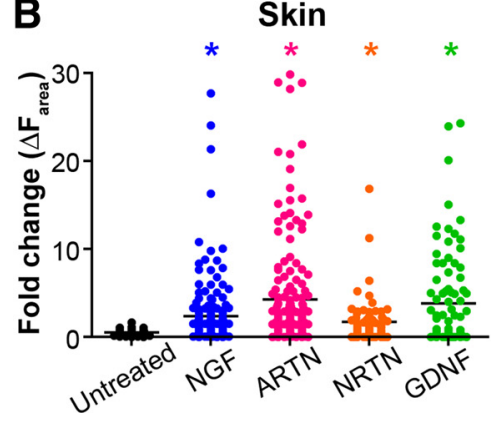

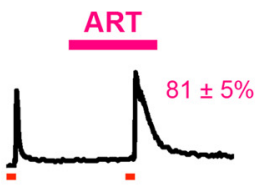
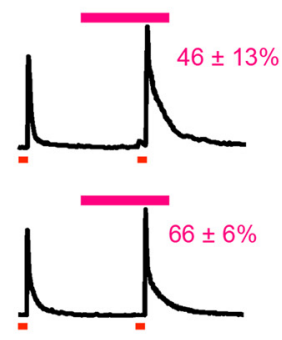

C

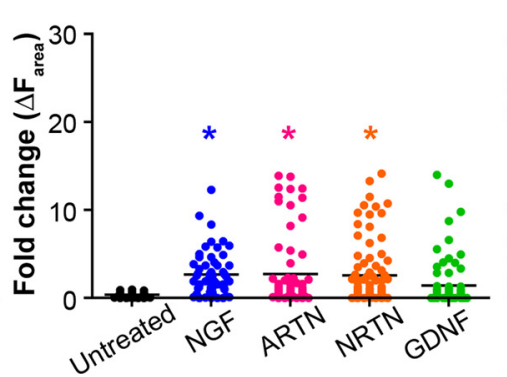

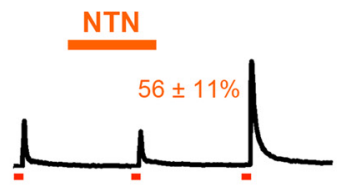
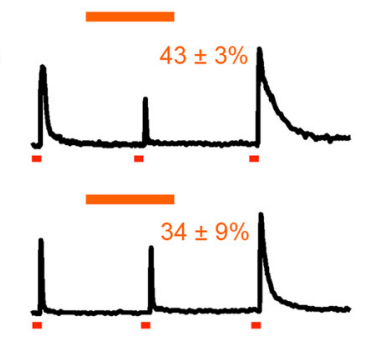

D
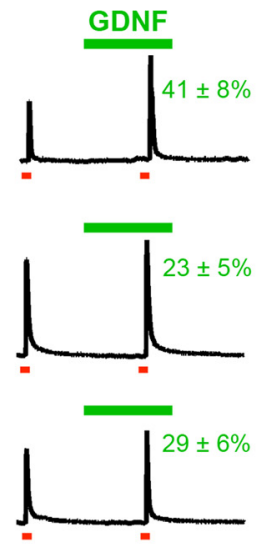

Colon

Figure 7. Growth factors differentially potentiate TRPV1 in target-defined sensory neurons. $\mathrm{Ca}^{2+}{ }^{2}$ imaging was used to determine the efficacy of NGF, ARTN, NRTN, or GDNF to potentiate capsaicin-evoked $\mathrm{Ca}^{2+}$ signals in retrogradely labeled skin, muscle, and colon DRG neurons. Examples of $\mathrm{Ca}^{2+}$ traces in response to capsaicin presentation before and after growth factor exposure are shown in $A$. Capsaicin $(1 \mu \mathrm{M})$ was applied at $10 \mathrm{~min}$ intervals with a $7 \mathrm{~min}$ application of growth factor $(100 \mathrm{ng} / \mathrm{ml})$ between the first and second capsaicin presentations. The percentage of capsaicin-responsive neurons potentiated by each growth factor is given above each representative trace. Fold changes in response area ( $\left.\Delta F_{\text {area }}\right)$ following growth factor application are shown for skin $(\boldsymbol{B})$, muscle $(\boldsymbol{C})$, and colon $(\boldsymbol{D})$ neurons. All four growth factors tested potentiate capsaicin responses in skin, muscle, and colon afferents; however, the prevalence and magnitude of the effects vary with target tissue. The greatest ARTN- and GDNF-induced potentiation is observed among skin afferents. ${ }^{*} p<0.05$ versus untreated; Mann-Whitney test.

Target-specific afferents respond to different combinations of growth factors

Previous studies have demonstrated that sensory neurons commonly express multiple growth factor receptors and are therefore responsive to more than one growth factor, the expression of which is largely target dependent and can be greatly increased or decreased in pathological states (Fig. 1). To determine the breadth of growth factor responsiveness of target-identified afferents, skin, muscle, and colon neurons were sequentially tested with all possible pairs of the four growth factors tested above (NGF, ARTN, NRTN, and GDNF) to evaluate their ability to potentiate capsaicin or mustard oil responses. No coverslip was tested with more than two growth factors and 30 min were allowed to elapse between growth factor applications, as we have previously demonstrated this interval sufficient to negate the effects of the first growth factor (Malin et al., 2006).

Analysis of capsaicin responses in skin neurons revealed that approximately one-half of the cells potentiated by ARTN were also potentiated by NGF (Fig. 9A), NRTN (Fig. 9D), or GDNF (Fig. 9E). Nearly every cutaneous afferent whose capsaicin response was potentiated by GDNF could also be potentiated by NGF (Fig. 9C), ARTN (Fig. 9E), or NRTN (Fig. 9F). Muscle afferents could be differentiated from cutaneous afferents in that there was a greater prevalence of NGF potentiation (Fig. 9A-C) and generally less overlap between growth factor potentiation of TRPV1 (Fig. 9A-F). Colon afferents were similar to muscle afferents, with the notable exception that $>90 \%$ of capsaicinresponsive colon neurons exhibited potentiation by either ARTN or GDNF, but no cells could be potentiated by both growth fac- tors (Fig. 9E). There was also a significantly smaller percentage of colon neurons that were potentiated by both ARTN and NRTN than observed among skin or muscle neurons (Fig. 9E). These data suggest a dichotomy in GFR $\alpha$ expression among populations of TRPV1-expressing colon afferents.

Within skin neurons, a significantly smaller percentage of mustard oil responses were potentiated by more than one growth factor (Fig. 10), compared with capsaicin responses (Fig. 9). Most strikingly, no mustard oil responses were potentiated by both NGF and NRTN (Fig. 10 B), yet all capsaicin responses potentiated by NGF were also potentiated by NRTN (Fig. 9B). Growth factor potentiation of mustard oil responses in colon neurons was not remarkably different from that of capsaicin responses, with the exception of a larger population responding to both NRTN and ARTN (Fig. 10D) or GDNF (Fig. 10F). Interestingly, nearly $90 \%$ of mustard oil responses in colon neurons were potentiated by ARTN or GDNF with no neurons potentiated by both (Fig. $10 E$ ), similar to capsaicin responses in the same population (Fig. $9 E$ ). Also of note is that nearly all TRPA1-expressing skin afferents are modulated by a growth factor, but most are modulated by only one [i.e., few neurons exhibited dual responsiveness when tested with growth factor pairs (Fig. 10)]. This is quite different from the picture in TRPA1 muscle afferents, where all tested afferents are modulated by a growth factor, and the majority by more than one.

No TRPA1-expressing skin afferents responded to both NGF and NRTN (Fig. $10 \mathrm{~B}$ ), whereas $>50 \%$ of TRPV1 skin afferents exhibited potentiation by both NGF and NRTN (compare Figs. $9 B, 10 B)$. Equally striking, GDNF did not potentiate TRPA1 in 
A

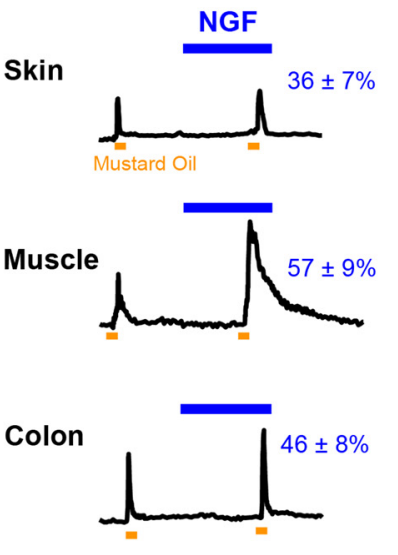

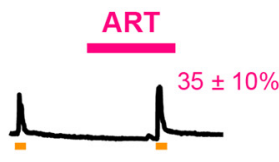
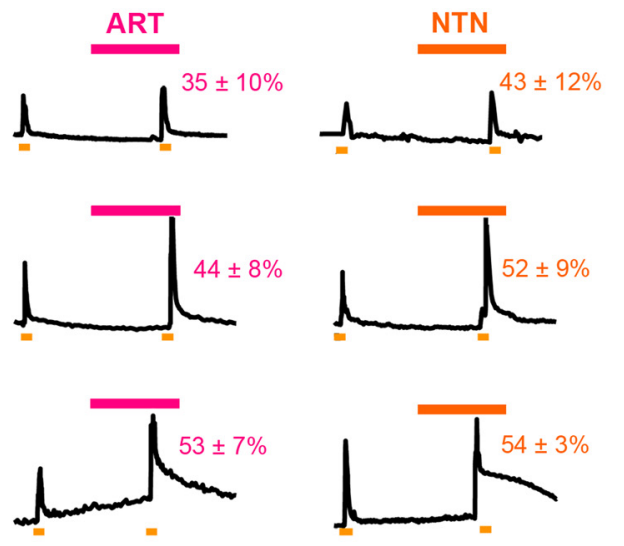
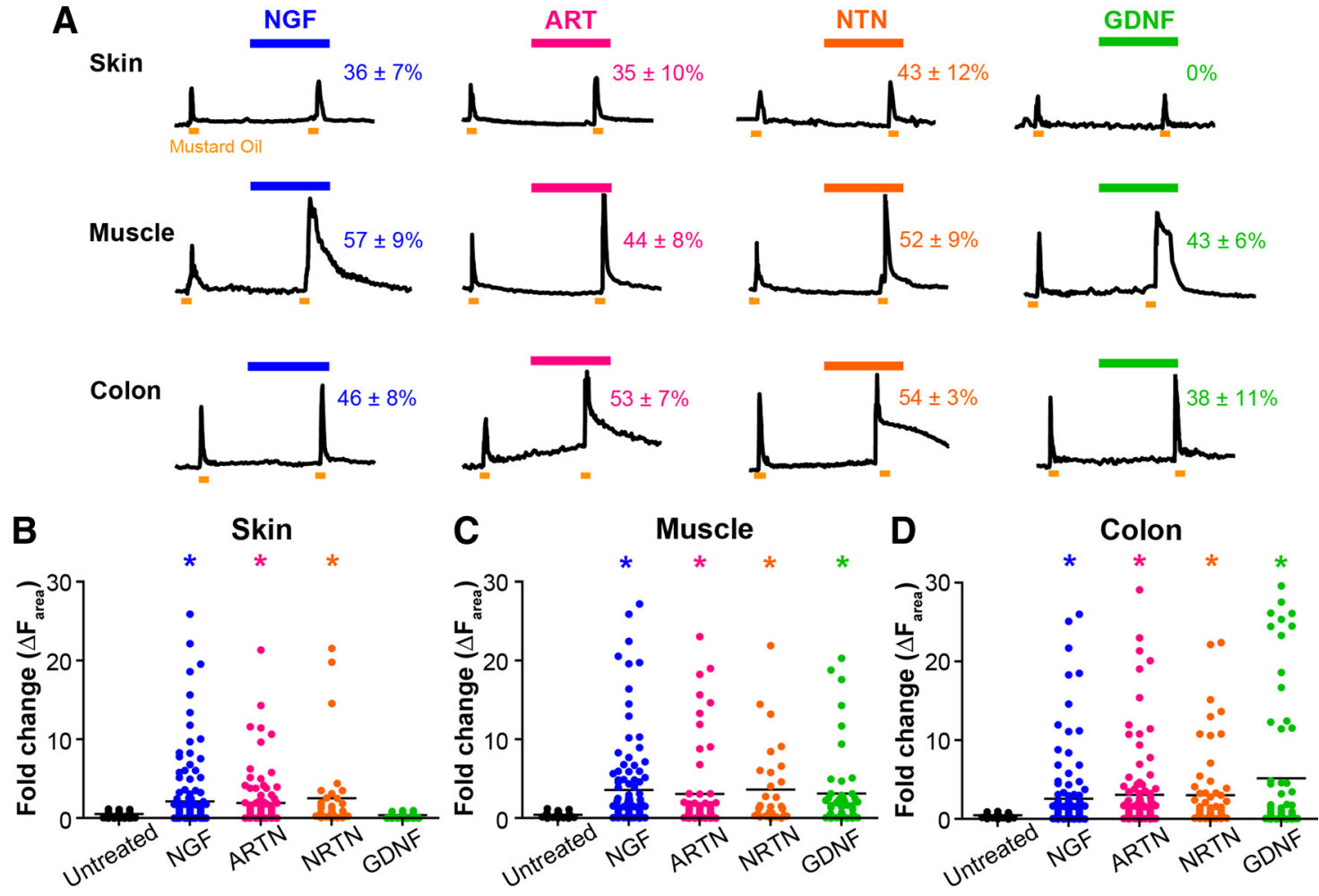

Figure 8. Growth factors differentially potentiate TRPA1 in target-defined sensory neurons. $\mathrm{Ca}^{2+}$ imaging was used to examine the efficacy of NGF, ARTN, NRTN, or GDNF to potentiate mustard oil-evoked $\mathrm{Ca}^{2+}$ signal in retrogradely labeled skin, muscle, and colon DRG neurons. Examples of $\mathrm{Ca}^{2+}$ traces in response to mustard oil presentation before and after growth factor exposure are shown in A. Mustard oil ( $100 \mu \mathrm{M}$ ) was applied at 10 min intervals with a 7 min application of growth factor ( $100 \mathrm{ng} / \mathrm{ml})$ between the first and second mustard oil presentations. The percentage of mustard oil-responsive neurons potentiated by each growth factor is given above each representative trace. Fold changes in response area ( $\left.\Delta F_{\text {area }}\right)$ following growth factor application are shown for skin $(\boldsymbol{B})$, muscle $(\boldsymbol{C})$, and colon $(\boldsymbol{D})$ neurons. Potentiation of TRPA1 by NGF, ARTN, or NRTN is comparable between all populations, whereas GDNF is ineffective at potentiating TRPA1 responses in skin neurons. ${ }^{*} p<0.05$ versus untreated; Mann-Whitney test.

Table 2. Percentage of cutaneous and muscle afferents expressing TRP channels and GFR $\alpha$ receptors

\begin{tabular}{lll}
\hline Gene(s) & \% Cutaneous $(n=32)$ & \% Muscle $(n=23)$ \\
\hline GFR $\alpha 1$ & 56 & 58 \\
GFR $\alpha 2$ & 56 & 24 \\
GFR $\alpha 2 /$ GFR $\alpha 1$ & 61 & 35 \\
TRPV1/GFR $\alpha 1$ & 39 & 42 \\
TRPA1/GFR $\alpha 1$ & 17 & 21 \\
TRPV1/GFR $\alpha 2$ & 17 & 50 \\
TRPA1/GFR $\alpha 2$ & 11 & 50
\end{tabular}

The percentage of GFR $\alpha 1$ - and GFR $\alpha 2$-expressing neurons are presented first followed by the percentage of GFR $\alpha 1$ - or GFR $\alpha 2$-expressing cells that also express a second gene (e.g., 39\% of cutaneous GFR $\alpha 1$-expressing neurons also express TRPV1).

skin afferents (Fig. 10C), whereas $40 \%$ of TRPV1-expressing afferents were potentiated by GDNF (Fig. 9C).

\section{Discussion}

Although activated by multiple stimuli, TRP channels are still best known for their ability to transduce thermal stimuli (McKemy et al., 2002; Jordt et al., 2003; Tominaga and Caterina, 2004; Caterina, 2007; Latorre et al., 2007; Willis, 2007) even though animals lacking functional TRPV1 or TRPA1 have little or no loss of thermal sensitivity (Caterina et al., 2000; Davis et al., 2000; Bautista et al., 2006; Kwan et al., 2006). The results presented here indicate that afferents that are normally not exposed to noxious temperatures (i.e., muscle and colon afferents) express TRPV1 and TRPA1 in higher percentages, exhibit larger agonistactivated calcium signals, and can exhibit greater growth factorinduced potentiation than that seen in afferents that commonly receive noxious thermal stimuli (i.e., cutaneous sensory neurons). This in no way diminishes the importance of these channels. On the contrary, our results suggest that these channels are more widely expressed and may be even more important for nociceptor function than previously thought.

\section{TRPV1 and TRPA1 are regulated by inflammation}

The data presented here confirm previous studies showing that both TRPV1 and TRPA1 mRNA in DRG are increased following CFA injection into the skin (Ji et al., 2002; Amaya et al., 2004; Obata et al., 2005; Malin et al., 2006; Diogenes et al., 2007; Xu et al., 2007) or TNBS inflammation in the colon (De Schepper et al., 2008a,b; Yang et al., 2008), but with differing time courses depending on the site of inflammation. Expression of NGF and GDNF family members is coincidentally increased in inflamed tissues and also with a distinct pattern of expression for cutaneous versus visceral structures. Linking these two observations together, we demonstrated that pretreatment of skin with growth factors potentiates nocifensive behaviors evoked by capsaicin or mustard oil application, suggesting that coordinated changes in growth factor expression during inflammation directly contribute to hyperalgesia by functional potentiation of TRPV1 and TRPA1.

\section{Distribution of functional TRPV1 and TRPA1 channels in primary sensory neurons}

One of the goals of the present study was to define the percentage of TRPV1- and TRPA1-expressing sensory neurons that innervate each of the examined target tissues. Because of the density of innervation, cutaneous and muscular structures are likely to ac- 


\section{Skin Muscle Colon}

A
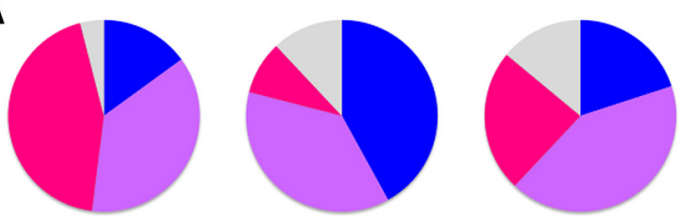

NGF

ARTN

NGF/ARTN

No effect

B
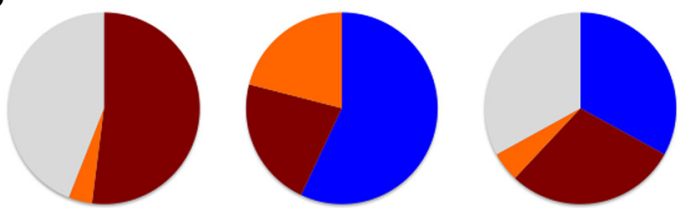

NGF

NRTN

NGF/NRTN

No effect

C
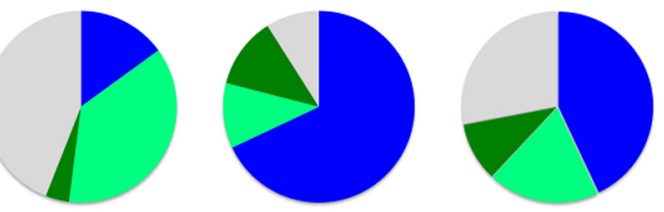

NGF

GDNF

NGF/GDNF

No effect

D
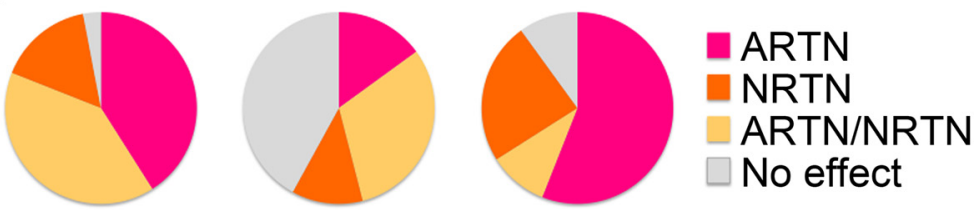

E
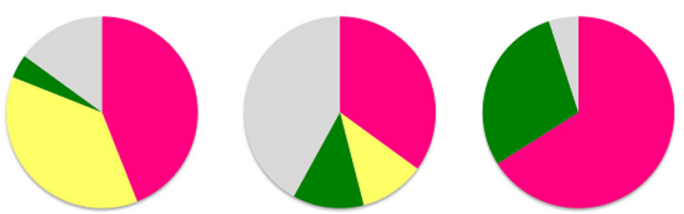

ARTN

GDNF

ARTN/GDNF No effect

$\mathbf{F}$
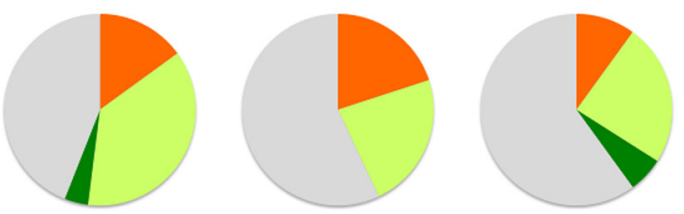

NRTN

GDNF

NRTN/GDNF

No effect

Figure 9. Growth factor potentiation profile of TRPV1 responses is target tissue dependent. $\mathrm{Ca}^{2+}$ imaging was used to determine the overlap of NGF, ARTN, NRTN, and GDNF potentiating effects on TRPV1 responses in retrogradely labeled skin, muscle, and colon DRG neurons. Capsaicin (1 $\mu \mathrm{m}$ ) was applied to obtain a baseline response followed by growth factor ( $100 \mathrm{ng} / \mathrm{ml})$ treatment for $7 \mathrm{~min}$ and a second application of capsaicin $(1 \mu \mathrm{M})$. Following a $30 \mathrm{~min}$ rest period to allow for recovery from the first growth factor treatment, the same protocol was repeated using a second growth factor. Fold changes in response area $\left(\Delta F_{\text {area }}\right)$ were calculated and the percentage of potentiated cells $\left(>1\right.$-fold change in $\Delta F_{\text {area }}$ ) was determined. Pie charts show the percentage of TRPV1-expressing afferents potentiated by each pair of growth factors for each target-defined population ( $n=811$ capsaicinresponsive neurons). The percentage of cells that responded to both NGF and ARTN (purple wedge) is similar ( $\sim 40 \%)$ in all target tissues $(\boldsymbol{A})$. Interestingly, TRPV1 responses in skin neurons were more likely to be potentiated by both growth factors in all pairs than in either muscle or colon afferents $(\boldsymbol{B}-\boldsymbol{F})$. The majority of TRPV1 responses in skin and colon neurons can be potentiated by ARTN ( $\boldsymbol{E}$, pink wedge) or GDNF (green wedge), and the overlap between the two growth factors (yellow wedge) is robust in skin afferents, constituting nearly every GDNF-responsive neuron, yet is completely absent in colon afferents.

count for the majority of all sensory neurons in a given DRG. Visceral afferents have been proposed to make up, at most, 5-8\% of all sensory neurons (Cervero, 1994; Gebhart and Bielefeldt, 2006). To assess the relative frequency of TRPV1 expression within skin, muscle, and colon neurons, we performed two different experiments. In the first, an unbiased survey was conducted of capsaicin responses in random fields of target-labeled isolated sensory neurons. Femoral muscle afferents accounted for $\sim 33 \%$ of all capsaicin-responsive neurons, whereas saphenous skin afferents accounted for only $15 \%$ of all capsaicin-responsive afferents. Colon afferents accounted for only $5 \%$ of all capsaicin- responsive neurons in L5-S1; however, there was a significantly higher percentage of capsaicin-responsive neurons within these ganglia, which primarily innervate visceral structures (Berkley et al., 1988, 1990; Baron and Jänig, 1991; Keast and De Groat, 1992; Berkley, 2005; Christianson et al., 2007), than observed in L2-L4, suggesting that TRPV1 is highly prevalent among visceral neurons. In the second experiment, backlabeled cells were tested individually for responses to TRPV1 or TRPA1 agonists. Again, the percentage of capsaicin and/or mustard oil responsive muscle or Colon neurons was over twice that of skin neurons. Because there are other pure cutaneous nerves as well as mixed nerves that arise from these ganglia, it is not possible to provide exact percentages of total skin, muscle, or colon TRPV1 and TRPA1 neurons present in L2-L4 or L5-S1 DRG. However, our results strongly suggest that muscle neurons constitute a substantially higher percentage of the TRPV1- and/or TRPA1expressing population of L2-L4 ganglia than do skin neurons. Interestingly, the extent of overlap between TRPV1 and TRPA1 varies between different target-identified populations: skin afferents show little overlap, while most colon and muscle afferents respond to both TRPV1 and TRPA1 agonists. This result suggests that previous reports of high overlap in TRPV1 and TRPA1 expression within total DRG may be reflecting data derived from muscle and visceral afferents, rather than skin afferents.

The structure(s) within the muscle and colon innervated by these fibers is unknown; however, one candidate is the vasculature. Most TRPV1 and TRPA1 afferents are peptidergic and virtually all vascular afferents express the neuropeptide CGRP and/or the ARTN receptor GFR $\alpha 3$ (Gibbins et al., 1985; Burnstock, 1987; Kruger et al., 1989; Holzer, 1998; Honma et al., 2002). Moreover, ARTN is normally expressed in the smooth muscle of arteries and arterioles (Honma et al., 2002). This raises the possibility that some "muscle" afferents do not directly innervate muscle fibers, but instead regulate muscle homeostasis, acting as metaboreceptive afferents (Light et al., 2008).

These results also reinforce the often-overlooked observation that TRPV 1 and TRPA 1 are expressed more widely than generally appreciated. IB4-binding DRG neurons are generally thought of as a distinct population of nociceptors that express Ret and do not overlap with neurons expressing TrkA, neuropeptides, and TRPV1 or TRPA1. However, this view of a simple dichotomy between peptidergic and nonpeptidergic neurons is misleading and belies the diversity of nociceptor populations (Carr et al., 1990). Ret is expressed in $60-65 \%$ of rat DRG neurons, including both nociceptors and large-diameter low-threshold mechanoreceptors, whereas IB4 binds 35-40\% of DRG neurons (Molliver 
and Snider, 1997; Bennett et al., 1998). Only approximately one-half of GFR $\alpha 1$ positive and $78 \%$ of GFR $\alpha 2$-positive neurons are IB4-positive. Multiple laboratories have identified a significant minority of neurons that coexpress Ret and TrkA (Bennett et al., 1998; Kashiba et al., 2003). The bulk of this population appears to express GFR $\alpha 3$, and nearly all GFR $\alpha 3$-positive neurons express TRPV1 (Orozco et al., 2001; Malin et al., 2006). Furthermore, 13\% of TrkA-positive neurons were reported to have binding sites for GDNF (Molliver and Snider, 1997), and up to $20 \%$ of TRPV 1 neurons in L4 ganglia express GFR $\alpha 2$ (Malin et al., 2006). Supporting a role for GFL in the modulation of TRPV1, administration of GDNF, NRTN, or ARTN increased capsaicinevoked CGRP release in vitro (Price et al., 2005; Schmutzler et al., 2009).

\section{Growth factors differentially potentiate} TRPV1 and TRPA1 responses

In this study, we report the novel finding that behavioral responses to TRPV1 and TRPA1 agonists are significantly enhanced by growth factor pretreatment. Both capsaicin and mustard oil responses showed significant tachyphylaxis that was blocked and/or potentiated by growth factors, a finding that, with the exception of NGF (Diogenes et al., 2007), has not been previously reported for TRPA1. Interestingly, the efficacy and scope of growth factor modulation of TRPV1 and TRPA1 was dependent on both the target tissue of the neuron and the ion channel examined. Growth factor potentiation of TRPV1 and TRPA1 in skin afferents is quite distinct, presumably due to the relatively low prevalence of TRP channel coexpression within this population, compared with muscle or colon neurons. TRPV1 is modulated most effectively by ARTN in skin afferents, whereas TRPA1 is potentiated equally by NGF, ARTN, or NRTN. GDNF does not potentiate TRPA1 in skin afferents, despite potentiating $\sim 40 \%$ of TRPV1 responses in the same population.

Growth factor potentiation of TRPV1 and TRPA1 within muscle afferents did not significantly vary, presumably due to the significant overlap in TRPV1 and TRPA1 expression. One exception was the observation that NGF alone potentiated a significantly larger proportion of TRPV1 responses within muscle neurons, whereas GDNF alone potentiated a significantly larger proportion of TRPA1 responses. Coexpression of both TRPV1 and TRPA1 was greatest among colon afferents $(\sim 60 \%)$, and, accordingly, these channels were similarly modulated by all four growth factors, with the exception of GDNF or NRTN alone potentiating a larger percentage of TRPA1 responses than TRPV1 responses. Furthermore, in both

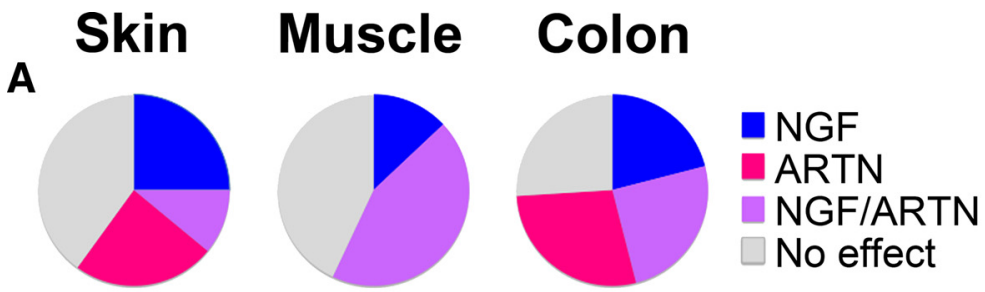

B
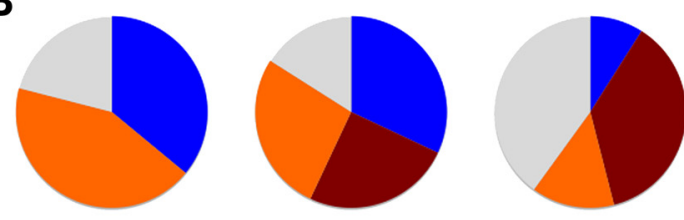

NGF

NRTN

NGF/NRTN

No effect

C
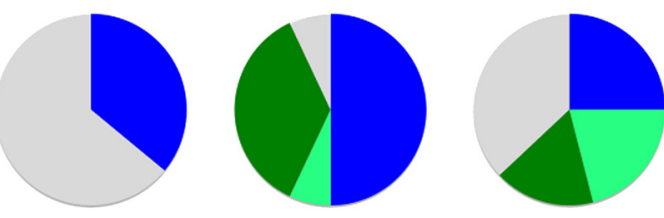

NGF

GDNF

NGF/GDNF

No effect

D
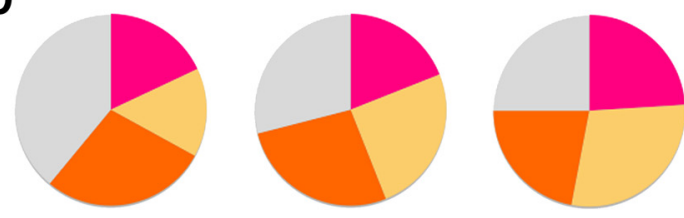

ARTN

NRTN

ARTN/NRTN

$\checkmark$ No effect

E
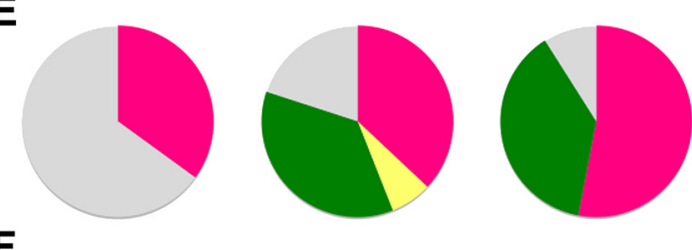

ARTN

GDNF

ARTN/GDNF

No effect

$\mathbf{F}$
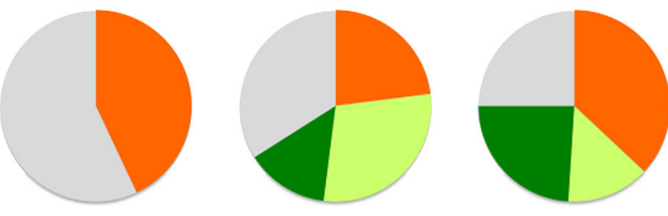

NRTN

GDNF

NRTN/GDNF

No effect

Figure 10. Growth factor potentiation profile of TRPA1 is target tissue dependent. $\mathrm{Ca}^{2+}$ imaging was used to determine the overlap of NGF, ARTN, NTRN, and GDNF potentiating effects on TRPA1 responses in isolated skin, muscle, and colon DRG neurons. Mustard oil $(100 \mu \mathrm{M})$ was applied to obtain a baseline response followed by growth factor $(100 \mathrm{ng} / \mathrm{ml})$ treatment for $7 \mathrm{~min}$ and a second mustard oil $(100 \mu \mathrm{m})$ application. Following a 30 min rest period to allow for recovery from the first growth factor treatment, the same protocol was repeated using a second growth factor. Fold changes in response area $\left(\Delta F_{\text {area }}\right)$ were calculated and the percentage of potentiated cells $\left(>1\right.$-fold change in $\Delta F_{\text {area }}$ ) was determined. Pie charts show the percentage of TRPA1expressing afferents potentiated by each pair of growth factors for each target-defined population ( $n=770$ mustard oilresponsive neurons). The percentage of TRPA1 responses potentiated by both NGF and ARTN ( $A$, purple wedge), as well as by both NRTN and GDNF ( $\boldsymbol{F}$, lime wedge), is significantly higher in muscle neurons than either skin or colon ( $p<0.01$; ANOVA with Dunnett's multiple-comparison test). TRPA1 responses potentiated by both NRTN and NGF ( $B$, brown wedge) aremostprevalent in colon neurons and completely absent in skin neurons. In fact, among skin neurons, only those TRPA1 responses potentiated by ARTN $(\boldsymbol{A}, \boldsymbol{D}, \boldsymbol{E}$, pink wedge) are also potentiated by another growth factor, with the exception of GDNF, which had no effect on TRPA1 responses in this population. Overlap between NGF and GDNF potentiation of TRPA1 is also greatest in colon afferents ( $\boldsymbol{C}$, turquoise wedge). Interestingly, even though nearly all TRPA1 responses in colon neurons are potentiated by either ARTN ( $\boldsymbol{E}$, pink wedge) or GDNF (green wedge) alone, no TRPA1 responses in this population are potentiated by both growth factors in the same neuron.

muscle and colon neurons, the magnitude of growth factor potentiation was significantly greater for TRPA1 than for TRPV1, suggesting that, despite their coexpression within the same neurons, TRPA1 may be more sensitive to growth factor modulation than TRPV1.

These studies were motivated in part by a growing realization that rigorous investigation of the mechanisms underlying primary afferent plasticity is unlikely to succeed if we assume that neurons expressing the same channels are regulated identically, re- 
gardless of their target tissue. Previous studies have shown that the same receptors and channels are commonly expressed by afferents innervating different structures and that the functional characteristics of these receptors and their modulation following inflammation or injury vary with the peripheral target of the afferent. For example, Oyelese and Kocsis (1996) reported significant differences in GABA conductance between skin and muscle afferents, both before and after nerve crush. Similarly, Gold and Traub (2004) reported significant differences in colon and skin afferents, including action potential threshold, rheobase, and sensitization by prostaglandin $E_{2}$. Together with the data presented here, this suggests that, to thoroughly understand the mechanisms underlying primary afferent sensitivity, one must take into account receptor/channel expression as well as the peripheral target of the afferent.

\section{References}

Akopian AN, Ruparel NB, Jeske NA, Hargreaves KM (2007) Transient receptor potential TRPA1 channel desensitization in sensory neurons is agonist dependent and regulated by TRPV1-directed internalization. J Physiol 583:175-193.

Amaya F, Oh-hashi K, Naruse Y, Iijima N, Ueda M, Shimosato G, Tominaga M, Tanaka Y, Tanaka M (2003) Local inflammation increases vanilloid receptor 1 expression within distinct subgroups of DRG neurons. Brain Res 963:190-196.

Amaya F, Shimosato G, Nagano M, Ueda M, Hashimoto S, Tanaka Y, Suzuki H, Tanaka M (2004) NGF and GDNF differentially regulate TRPV1 expression that contributes to development of inflammatory thermal hyperalgesia. Eur J Neurosci 20:2303-2310.

Baron R, Jänig W (1991) Afferent and sympathetic neurons projecting into lumbar visceral nerves of the male rat. J Comp Neurol 314:429-436.

Bautista DM, Movahed P, Hinman A, Axelsson HE, Sterner O, Högestätt ED, Julius D, Jordt SE, Zygmunt PM (2005) Pungent products from garlic activate the sensory ion channel TRPA1. Proc Natl Acad Sci U S A 102:12248-12252.

Bautista DM, Jordt SE, Nikai T, Tsuruda PR, Read AJ, Poblete J, Yamoah EN, Basbaum AI, Julius D (2006) TRPA1 mediates the inflammatory actions of environmental irritants and proalgesic agents. Cell 124:1269-1282.

Bennett DL, Michael GJ, Ramachandran N, Munson JB, Averill S, Yan Q, McMahon SB, Priestley JV (1998) A distinct subgroup of small DRG cells express GDNF receptor components and GDNF is protective for these neurons after nerve injury. J Neurosci 18:3059-3072.

Berkley KJ (2005) A life of pelvic pain. Physiol Behav 86:272-280.

Berkley KJ, Robbins A, Sato Y (1988) Afferent fibers supplying the uterus in the rat. J Neurophysiol 59:142-163.

Berkley KJ, Hotta H, Robbins A, Sato Y (1990) Functional properties of afferent fibers supplying reproductive and other pelvic organs in pelvic nerve of female rat. J Neurophysiol 63:256-272.

Berkley KJ, Rapkin AJ, Papka RE (2005) The pains of endometriosis. Science 308:1587-1589.

Bielefeldt K, Ozaki N, Gebhart GF (2003) Role of nerve growth factor in modulation of gastric afferent neurons in the rat. Am J Physiol Gastrointest Liver Physiol 284:G499-G507.

Burns K, Clatworthy J, Martin L, Martinon F, Plumpton C, Maschera B, Lewis A, Ray K, Tschopp J, Volpe F (2000) Tollip, a new component of the IL-1RI pathway, links IRAK to the IL-1 receptor. Nat Cell Biol 2:346-351.

Burnstock G (1987) Mechanisms of interaction of peptide and nonpeptide vascular neurotransmitter systems. J Cardiovasc Pharmacol 10 [Suppl 12]:S74-S81.

Carr PA, Yamamoto T, Nagy JI (1990) Calcitonin gene-related peptide in primary afferent neurons of rat: co-existence with fluoride-resistant acid phosphatase and depletion by neonatal capsaicin. Neuroscience 36:751-760.

Caterina MJ (2007) Transient receptor potential ion channels as participants in thermosensation and thermoregulation. Am J Physiol Regul Integr Comp Physiol 292:R64-R76.

Caterina MJ, Schumacher MA, Tominaga M, Rosen TA, Levine JD, Julius D (1997) The capsaicin receptor: a heat-activated ion channel in the pain pathway. Nature 389:816-824.

Caterina MJ, Leffler A, Malmberg AB, Martin WJ, Trafton J, Petersen-Zeitz KR, Koltzenburg M, Basbaum AI, Julius D (2000) Impaired nociception and pain sensation in mice lacking the capsaicin receptor. Science 288:306-313.
Cervero F (1994) Sensory innervation of the viscera: peripheral basis of visceral pain. Physiol Rev 74:95-138.

Christianson JA, Traub RJ, Davis BM (2006a) Differences in spinal distribution and neurochemical phenotype of colonic afferents in mouse and rat. J Comp Neurol 494:246-259.

Christianson JA, McIlwrath SL, Koerber HR, Davis BM (2006b) Transient receptor potential vanilloid 1-immunopositive neurons in the mouse are more prevalent within colon afferents compared to skin and muscle afferents. Neuroscience 140:247-257.

Christianson JA, Liang R, Ustinova EE, Davis BM, Fraser MO, Pezzone MA (2007) Convergence of bladder and colon sensory innervation occurs at the primary afferent level. Pain 128:235-243

Ciarrocchi A, D’Angelo R, Cordiglieri C, Rispoli A, Santi S, Riccio M, Carone S, Mancia AL, Paci S, Cipollini E, Ambrosetti D, Melli M (2009) Tollip is a mediator of protein sumoylation. PLoS One 4:e4404.

Davis JB, Gray J, Gunthorpe MJ, Hatcher JP, Davey PT, Overend P, Harries MH, Latcham J, Clapham C, Atkinson K, Hughes SA, Rance K, Grau E, Harper AJ, Pugh PL, Rogers DC, Bingham S, Randall A, Sheardown SA (2000) Vanilloid receptor-1 is essential for inflammatory thermal hyperalgesia. Nature 405:183-187.

De Schepper HU, De Man JG, Ruyssers NE, Deiteren A, Van Nassauw L, Timmermans JP, Martinet W, Herman AG, Pelckmans PA, De Winter BY (2008a) TRPV1 receptor signaling mediates afferent nerve sensitization during colitis-induced motility disorders in rats. Am J Physiol Gastrointest Liver Physiol 294:G245-G253.

De Schepper HU, De Winter BY, Van Nassauw L, Timmermans JP, Herman AG, Pelckmans PA, De Man JG (2008b) TRPV1 receptors on unmyelinated C-fibres mediate colitis-induced sensitization of pelvic afferent nerve fibres in rats. J Physiol 586:5247-5258.

Diogenes A, Akopian AN, Hargreaves KM (2007) NGF up-regulates TRPA1: implications for orofacial pain. J Dent Res 86:550-555.

Elitt CM, McIlwrath SL, Lawson JJ, Malin SA, Molliver DC, Cornuet PK, Koerber HR, Davis BM, Albers KM (2006) Artemin overexpression in skin enhances expression of TRPV1 and TRPA1 in cutaneous sensory neurons and leads to behavioral sensitivity to heat and cold. J Neurosci 26:8578-8587.

Elitt CM, Malin SA, Koerber HR, Davis BM, Albers KM (2008) Overexpression of artemin in the tongue increases expression of TRPV1 and TRPA1 in trigeminal afferents and causes oral sensitivity to capsaicin and mustard oil. Brain Res 1230:80-90.

Fasanella KE, Christianson JA, Chanthaphavong RS, Davis BM (2008) Distribution and neurochemical identification of pancreatic afferents in the mouse. J Comp Neurol 509:42-52.

Gebhart GF, Bielefeldt K (2006) Visceral pain: basic mechanisms. In: Wall and Melzack's textbook of pain, Ed 5 (McMahon SB, Koltzenburg M, eds), pp 721-736. Philedephia: Elsevier.

Gibbins IL, Furness JB, Costa M, MacIntyre I, Hillyard CJ, Girgis S (1985) Co-localization of calcitonin gene-related peptide-like immunoreactivity with substance $P$ in cutaneous, vascular and visceral sensory neurons of guinea pigs. Neurosci Lett 57:125-130.

Glabinski AR, Bielecki B, Kolodziejski P, Han Y, Selmaj K, Ransohoff RM (2003) TNF-alpha microinjection upregulates chemokines and chemokine receptors in the central nervous system without inducing leukocyte infiltration. J Interferon Cytokine Res 23:457-466.

Gold MS, Traub RJ (2004) Cutaneous and colonic rat DRG neurons differ with respect to both baseline and PGE2-induced changes in passive and active electrophysiological properties. J Neurophysiol 91:2524-2531.

Holzer P (1998) Neurogenic vasodilatation and plasma leakage in the skin. Gen Pharmacol 30:5-11.

Honma Y, Araki T, Gianino S, Bruce A, Heuckeroth R, Johnson E, Milbrandt J (2002) Artemin is a vascular-derived neurotropic factor for developing sympathetic neurons. Neuron 35:267-282.

Ji RR, Samad TA, Jin SX, Schmoll R, Woolf CJ (2002) p38 MAPK activation by NGF in primary sensory neurons after inflammation increases TRPV1 levels and maintains heat hyperalgesia. Neuron 36:57-68.

Jordt SE, McKemy DD, Julius D (2003) Lessons from peppers and peppermint: the molecular logic of thermosensation. Curr Opin Neurobiol 13:487-492.

Kashiba H, Uchida Y, Senba E (2003) Distribution and colocalization of NGF and GDNF family ligand receptor mRNAs in dorsal root and nodose ganglion neurons of adult rats. Brain Res Mol Brain Res 110:52-62.

Keast JR, De Groat WC (1992) Segmental distribution and peptide content 
of primary afferent neurons innervating the urogenital organs and colon of male rats. J Comp Neurol 319:615-623.

Kobayashi K, Fukuoka T, Obata K, Yamanaka H, Dai Y, Tokunaga A, Noguchi K (2005) Distinct expression of TRPM8, TRPA1, and TRPV1 mRNAs in rat primary afferent neurons with $\mathrm{a} \delta / \mathrm{c}-$ fibers and colocalization with trk receptors. J Comp Neurol 493:596-606.

Kruger L, Silverman JD, Mantyh PW, Sternini C, Brecha NC (1989) Peripheral patterns of calcitonin-gene-related peptide general somatic sensory innervation: cutaneous and deep terminations. J Comp Neurol 280:291-302.

Kwan KY, Allchorne AJ, Vollrath MA, Christensen AP, Zhang DS, Woolf CJ, Corey DP (2006) TRPAl contributes to cold, mechanical, and chemical nociception but is not essential for hair-cell transduction. Neuron 50:277-289.

Latorre R, Brauchi S, Orta G, Zaelzer C, Vargas G (2007) ThermoTRP channels as modular proteins with allosteric gating. Cell Calcium 42:427-438.

Lawson SN (1992) Morphological and biochemical cell types of sensory neurons. In: Sensory neurons, diversity, development and plasticity (Scott SA, ed), pp 27-59. New York: Oxford.

Lewin GR, Mendell LM (1994) Regulation of cutaneous C-fiber heat nociceptors by nerve growth factor in the developing rat. J Neurophysiol 71:941-949.

Lewin GR, Rueff A, Mendell LM (1994) Peripheral and central mechanisms of NGF-induced hyperalgesia. Eur J Neurosci 6:1903-1912.

Light AR, Hughen RW, Zhang J, Rainier J, Liu Z, Lee J (2008) Dorsal root ganglion neurons innervating skeletal muscle respond to physiological combinations of protons, ATP, and lactate mediated by ASIC, P2X, and TRPV1. J Neurophysiol 100:1184-1201.

Lindfors PH, Võikar V, Rossi J, Airaksinen MS (2006) Deficient nonpeptidergic epidermis innervation and reduced inflammatory pain in glial cell line-derived neurotrophic factor family receptor $\alpha 2$ knock-out mice. J Neurosci 26:1953-1960.

Livak KJ, Schmittgen TD (2001) Analysis of relative gene expression data using real-time quantitative PCR and the $2^{-\Delta \Delta C(T)}$ method. Methods 25:402-408.

Lu J, Zhou XF, Rush RA (2001) Small primary sensory neurons innervating epidermis and viscera display differential phenotype in the adult rat. Neurosci Res 41:355-363.

Malin SA, Molliver DC, Koerber HR, Cornuet P, Frye R, Albers KM, Davis BM (2006) Glial cell line-derived neurotrophic factor family members sensitize nociceptors in vitro and produce thermal hyperalgesia in vivo. J Neurosci 26:8588-8599.

Malin SA, Davis BM, Molliver DC (2007) Production of dissociated sensory neuron cultures and considerations for their use in studying neuronal function and plasticity. Nat Protoc 2:152-160.

McKemy DD, Neuhausser WM, Julius D (2002) Identification of a cold receptor reveals a general role for TRP channels in thermosensation. Nature 416:52-58.

Molliver DC, Snider WD (1997) Nerve growth factor receptor TrkA is down-regulated during postnatal development by a subset of dorsal root ganglion neurons. J Comp Neurol 381:428-438.

Molliver DC, Radeke MJ, Feinstein SC, Snider WD (1995) Presence or absence of TrkA protein distinguishes subsets of small sensory neurons with unique cytochemical characteristics and dorsal horn projections. J Comp Neurol 361:404-416.

Molliver DC, Lindsay J, Albers KM, Davis BM (2005) Overexpression of NGF or GDNF alters transcriptional plasticity evoked by inflammation. Pain 113:277-284.

Obata K, Katsura H, Mizushima T, Yamanaka H, Kobayashi K, Dai Y, Fukuoka T, Tokunaga A, Tominaga M, Noguchi K (2005) TRPA1 induced in sensory neurons contributes to cold hyperalgesia after inflammation and nerve injury. J Clin Invest 115:2393-2401.

Oh SB, Tran PB, Gillard SE, Hurley RW, Hammond DL, Miller RJ (2001) Chemokines and glycoprotein 120 produce pain hypersensitivity by directly exciting primary nociceptive neurons. J Neurosci 21:5027-5035.

Orozco OE, Walus L, Sah DW, Pepinsky RB, Sanicola M (2001) GFRalpha3 is expressed predominantly in nociceptive sensory neurons. Eur J Neurosci 13:2177-2182.

Ota M, Katsuyama Y, Hamano H, Umemura T, Kimura A, Yoshizawa K, Kiyosawa K, Fukushima H, Bahram S, Inoko H, Kawa S (2007) Two critical genes (HLA-DRB1 and ABCF1) in the HLA region are associated with the susceptibility to autoimmune pancreatitis. Immunogenetics 59:45-52.
Oyelese AA, Kocsis JD (1996) GABA $_{\mathrm{A}}$-receptor-mediated conductance and action potential waveform in cutaneous and muscle afferent neurons of the adult rat: differential expression and response to nerve injury. J Neurophysiol 76:2383-2392.

Paytubi S, Wang X, Lam YW, Izquierdo L, Hunter MJ, Jan E, Hundal HS, Proud CG (2009) ABC50 promotes translation initiation in mammalian cells. J Biol Chem 284:24061-24073.

Price TJ, Louria MD, Candelario-Soto D, Dussor GO, Jeske NA, Patwardhan AM, Diogenes A, Trott AA, Hargreaves KM, Flores CM (2005) Treatment of trigeminal ganglion neurons in vitro with NGF, GDNF or BDNF: effects on neuronal survival, neurochemical properties and TRPV1mediated neuropeptide secretion. BMC Neurosci 6:4.

Richard M, Drouin R, Beaulieu AD (1998) ABC50, a novel human ATPbinding cassette protein found in tumor necrosis factor-alpha-stimulated synoviocytes. Genomics 53:137-145.

Robinson DR, McNaughton PA, Evans ML, Hicks GA (2004) Characterization of the primary spinal afferent innervation of the mouse colon using retrograde labelling. Neurogastroenterol Motil 16:113-124.

Schmittgen TD, Livak KJ (2008) Analyzing real-time PCR data by the comparative $C_{T}$ method. Nat Protoc 3:1101-1108.

Schmutzler BS, Roy S, Hingtgen CM (2009) Glial cell line-derived neurotrophic factor family ligands enhance capsaicin-stimulated release of calcitonin gene-related peptide from sensory neurons. Neuroscience 161:148-156.

Semov A, Semova N, Lacelle C, Marcotte R, Petroulakis E, Proestou G, Wang E (2002) Alterations in TNF- and IL-related gene expression in spaceflown WI38 human fibroblasts. FASEB J 16:899-901.

Shu X, Mendell LM (1999) Nerve growth factor acutely sensitizes the response of adult rat sensory neurons to capsaicin. Neurosci Lett 274:159-162.

Subang MC, Richardson PM (2001) Influence of injury and cytokines on synthesis of monocyte chemoattractant protein-1 mRNA in peripheral nervous tissue. Eur J Neurosci 13:521-528.

Tominaga M, Caterina MJ (2004) Thermosensation and pain. J Neurobiol 61:3-12.

Wang HF, Shortland P, Park MJ, Grant G (1998) Retrograde and transganglionic transport of horseradish peroxidase-conjugated cholera toxin $\mathrm{B}$ subunit, wheatgerm agglutinin and isolectin B4 from Griffonia simplicifolia I in primary afferent neurons innervating the rat urinary bladder. Neuroscience 87:275-288.

White FA, Sun J, Waters SM, Ma C, Ren D, Ripsch M, Steflik J, Cortright DN, Lamotte RH, Miller RJ (2005) Excitatory monocyte chemoattractant protein-1 signaling is up-regulated in sensory neurons after chronic compression of the dorsal root ganglion. Proc Natl Acad Sci U S A 102: 14092-14097.

Wick EC, Hoge SG, Grahn SW, Kim E, Divino LA, Grady EF, Bunnett NW, Kirkwood KS (2006) Transient receptor potential vanilloid 1, calcitonin gene-related peptide, and substance P mediate nociception in acute pancreatitis. Am J Physiol Gastrointest Liver Physiol 290:G959-G969.

Willis WD Jr (2007) The somatosensory system, with emphasis on structures important for pain. Brain Res Rev 55:297-313.

Winston J, Shenoy M, Medley D, Naniwadekar A, Pasricha PJ (2007) The vanilloid receptor initiates and maintains colonic hypersensitivity induced by neonatal colon irritation in rats. Gastroenterology 132:615-627.

Woodbury CJ, Zwick M, Wang S, Lawson JJ, Caterina MJ, Koltzenburg M, Albers KM, Koerber HR, Davis BM (2004) Nociceptors lacking TRPV1 and TRPV2 have normal heat responses. J Neurosci 24:6410-6415.

Woolf CJ, Safieh-Garabedian B, Ma QP, Crilly P, Winter J (1994) Nerve growth factor contributes to the generation of inflammatory sensory hypersensitivity. Neuroscience 62:327-331.

Xu GY, Winston JH, Shenoy M, Yin H, Pendyala S, Pasricha PJ (2007) Transient receptor potential vanilloid 1 mediates hyperalgesia and is up-regulated in rats with chronic pancreatitis. Gastroenterology 133:1282-1292.

Yang J, Li Y, Zuo X, Zhen Y, Yu Y, Gao L (2008) Transient receptor potential ankyrin-1 participates in visceral hyperalgesia following experimental colitis. Neurosci Lett 440:237-241.

Zwick M, Davis BM, Woodbury CJ, Burkett JN, Koerber HR, Simpson JF, Albers KM (2002) Glial cell line-derived neurotrophic factor is a survival factor for isolectin B4-positive, but not vanilloid receptor 1-positive, neurons in the mouse. J Neurosci 22:4057-4065. 